\title{
Influence of Aerospace Standard Surface Pretreatment on the Intermetallic Phases and CeCC of 2024-T3 Al-Cu Alloy
}

\author{
Juan Jesús Alba-Galvín ${ }^{1}{ }^{1}$, Leandro González-Rovira ${ }^{1} * \mathbb{1}$, Manuel Bethencourt ${ }^{2} \mathbb{\text { , }}$, \\ Francisco Javier Botana ${ }^{1}$ and José María Sánchez-Amaya ${ }^{1}$ \\ 1 Department of Materials Science, Metallurgical Engineering and Inorganic Chemistry, Engineering School, \\ Universidad de Cádiz, 11519 Puerto Real (Cádiz), Spain; juanjesus.alba@uca.es (J.J.A.-G.); \\ javier.botana@uca.es (F.J.B.); josemaria.sanchez@uca.es (J.M.S.-A.) \\ 2 Department of Materials Science, Metallurgical Engineering and Inorganic Chemistry, \\ Faculty of Marine and Environmental Sciences, Universidad de Cádiz, \\ International Campus of Excellence of the Sea (CEI-MAR), 11510 Puerto Real (Cádiz), Spain; \\ manuel.bethencourt@uca.es \\ * Correspondence: leandro.gonzalez@uca.es; Tel.: +34-956-016-762
}

Received: 1 February 2019; Accepted: 7 March 2019; Published: 12 March 2019

\begin{abstract}
A standard three-step surface pretreatment employed in the aerospace sector for $\mathrm{Al}$ alloys have been investigated prior to the generation of cerium conversion coatings (CeCC) on aluminiumcopper alloy 2024. Two pretreatments were analysed, one without final acid etching (Pretreatment 1) and another with this step (Pretreatment 2). Both pretreatments affect the alloy intermetallic phases, playing a key role in the development of the $\mathrm{CeCC}$, and also in the susceptibility to localised corrosion in $\mathrm{NaCl}$ medium. Scanning electron microscopy coupled with energy-dispersive $\mathrm{X}$-ray analysis (SEM-EDX) revealed that after Pretreatment 2, $\mathrm{Al}(\mathrm{Cu}, \mathrm{Mg})$ phases were partially or totally removed through dealloying with their subsequent copper enrichment. Conversely, none of these intermetallic phases were affected when the final acid step was not employed (Pretreatment 1). Meanwhile, Al-Cu-Fe-Mn-(Si) phases, the other major Al-Cu alloys intermetallics, suffers minor changes through the whole pretreatments chain. The protective efficiency of CeCC was evaluated using electrochemical techniques based on linear polarisation (LP) and electrochemical impedance spectroscopy (EIS). Samples with CeCC deposited after the Pretreatment 1 gave higher polarisation resistance and impedance module than CeCC deposited after Pretreatment 2. SEM-EDX and X-ray photoelectron spectroscopy analysis (XPS) indicate that the main factors explaining the corrosion resistance of the coatings is the existence of $\mathrm{Al}(\mathrm{Cu}, \mathrm{Mg})$ intermetallics in the surface of the alloy, which promote the deposition of a cerium-based coating rich in $\mathrm{Ce}^{4+}$ compounds. These $\mathrm{Al}(\mathrm{Cu}, \mathrm{Mg})$ intermetallics were kept in the 2024 alloy when acid etching was not employed (Pretreatment 1).
\end{abstract}

Keywords: aluminium; alloy phases; corrosion; surface pretreatments; $\mathrm{CeCC}$

\section{Introduction}

Al-Cu alloys, commonly employed in the aerospace industry, offer excellent mechanical properties to weight ratios. Despite their excellent mechanical properties, provided by the alloying elements, these alloys suffer from localised corrosion problems, especially in chloride-containing media. In fact, the intermetallic particles provide sites on the substrate surface where $\mathrm{O}_{2}$ reduction can take place, leading to corrosion such as pitting or filiform corrosion. The principal alloy phases in 2024 are $\mathrm{Al}(\mathrm{Cu}, \mathrm{Mg})$ and $\mathrm{Al}-\mathrm{Cu}-\mathrm{Fe}-\mathrm{Mn}-\mathrm{Si}[1-7]$, with different stoichiometry depending on the author consulted. As a consequence, $\mathrm{Al}-\mathrm{Cu}$ alloys surfaces are often treated in order to reduce the corrosion extension. 
There are many surface treatments employed. Among them, chromates have traditionally been employed as inhibitors in closed systems and paints, in Cr-based chemical conversion coatings (CrCC), and in anodising and sealing baths [8-10]. However, hexavalent Chromium presents toxicity and carcinogenic properties, being prohibited by REACH (Registration, Evaluation, Authorisation and Restriction of Chemicals) and other regulations. These restrictions have obliged all sectors of industry to re-orientate their operational philosophy towards the use of processes that are not aggressive to the environment [8,11-13].

The case of $\mathrm{CrCC}$ is especially serious because there is no commercial alternative yet. One of the everlasting candidates for conversion coating replacement are Ce-based compounds (CeCC) $[10,14]$. However, as stated in an extensive review [15], there are still uncertainties in this technology that limit its commercial use. One of the gaps detected is that relatively little work has been carried out regarding the effect of pretreatments on the Ce coating, even though it is well known that pretreatments alter the morphology and chemistry of the alloy surface, and subsequently affect the deposition process and the properties of the Ce-based layer [16-20].

Authors usually apply their own or borrowed recipes without much scientific support for the choices that are made [15]. Some of the pretreatments found in the literature are commercial products employed in the aerospace sector according to standards developed in this field [20]. One of the most common standard chains of pretreatments, Airbus Specification i+D-P-072 [21], comprises three steps:

i. Turco 6849: a silicate-containing alkaline degreaser, formulated to remove shop soils, marking inks, cosmoline, grease and lube oils from ferrous and non-ferrous alloys. According to the standard, this treatment is used only to avoid contaminating the following two baths.

ii. Turco 4215 NC-LT: a free of chromate and silicate alkaline etching, developed for cleaning ferrous and nonferrous alloys by spray, immersion and ultrasonic methods at low temperatures.

iii. Turco Smut Go NC: an oxidising acid pickling, formulated to deoxidize and to desmut aluminium alloys by immersion in order to obtain a low surface resistance prior to anodising or conversion coatings.

Although there are studies employing some of these three product as pretreatment before a variety of corrosion preventive treatment, only some of them focus on the changes produced by these products on aluminium alloys, beyond those claimed by the chemical manufacturer. Additionally, as far as the authors are aware, there are no published articles describing the effects of these three consecutive treatments $(\mathrm{i}+\mathrm{ii}+\mathrm{iii})$ on the CeCC coatings formed on 2024-T3 alloy.

Swain et al. [22] described the employment of Turco 6849 plus Turco Smut Go NC as pretreatment before trivalent chromium process (TCP) on AA2024-T3. It is worth observing that the authors did not mention the concentration of Smut Go employed. The fluoride ions of Smut Go cause alumina layer breakdown and dissolution around $\mathrm{Cu}$-rich alloy phases, increasing surface roughening, pit density and pit depth with increasing treatment time. Dealloying of the $\mathrm{Al}(\mathrm{CuMg})$ phases also occurs during deoxidation in Smut Go, giving rise to more noble $\mathrm{Cu}$ particles at the bottom of pits.

Guo et al. [23] made also use of Turco 6849 followed by Turco Smut Go NC as pretreatments before TCP formation on AA2024-T3. XPS analyses and SEM observation revealed that alkaline etching by Turco 6849 resulted in a reduction of the amount of contaminant particles. A gentle dissolution of the surface is also reported, although Turco 6849 does not dissolve the characteristic rolling lines and pits on the as received surface. After $5 \mathrm{~min}$ of acid desmutting using Smut Go NC, the surface exhibited pits of hundreds of nanometers in diameter or larger over the entire surface. The authors stated that alloy intermetallic phases were totally or partially removed due to the dissolution of aluminium matrix adjacent to them.

R. Viroulaud et al. [24] studied the influence of surface pretreatments again on TCP over 2024-T3 aluminium alloy. They selected Sococlean A 3431 solution (provided by Socomore) as degreaser followed by pickling in Turco Smut Go NC. They concluded that the pickling pretreatment provokes 
a reduction of $\mathrm{Al}$ oxide thickness and a strong metallic copper enrichment at the surface of the 2024 alloy, associated with chemical dissolution of Al-Cu alloy phases.

Pinc et al. [25] studied the deposition of cerium conversion coating after immersion in Turco 4215 NC-LT. The results obtained showed that the surface composition of Al 2024-T3 changed after the immersion. The concentration of magnesium at the surface decreased from $30 \%$ down to $20 \%$ (at. \%) and the oxide thickness slightly decreased from 30 to around $25 \mathrm{~nm}$. The concentration of copper at the surface, however, remained very low, as it was in the non-treated surface. Therefore, an oxide coating, mainly aluminium and magnesium oxides, was present after alkaline cleaning in Turco 4215 NC-LT.

The standard treatment comprising Turco 6849, 4215 NC-LT and Smut Go NC is employed by many subcontractors of Airbus in a number of surface treatment lines, not only in CrCC. Therefore, the industries seek for coating technologies "greener" than chromates but also compatible with the same pretreatments currently approved. Otherwise, the investments required to adapt the protective bath lines must include the pretreatments baths as well. Consequently, a better understanding of the influence of this common standard treatment is of high interest in the aerospace sector in order to design alternative methods to the use of $\mathrm{Cr}(\mathrm{VI})$ for the development of conversion layers.

As observed in the short review described above, there is scarce literature devoted to the study of this particular industrial standard pretreatment procedure, and even less devoted to analysing their suitability before cerium conversion coating application.

Within this context, the objective of this paper is to investigate the effect of a standard surface pretreatment for aluminium alloys in the aerospace sector on the 2024-T3 surface and its subsequent influence in the formation of $\mathrm{CeCC}$. In particular, the effect of the application of two pretreatments procedures, was deeply analysed. The first one, so-called Pretreatment 1, involves the use of two consecutive baths (Henkel/Turco 6849 and Henkel/Turco 4215 NC-LT). The second one, Pretreatment 2, includes the three consecutive immersion pretreatments (Henkel/Turco 6849, Henkel/Turco 4215 NC-LT and Henkel/Turco Smut Go NC). Subsequently, the samples after Pretreatments 1 or 2 were treated by immersion in $\mathrm{CeCl}_{3} \cdot 7 \mathrm{H}_{2} \mathrm{O}$ chemically activated with $\mathrm{H}_{2} \mathrm{O}_{2}$. Samples were characterised by means of Scanning Electron Microscopy coupled with Energy-Dispersive X-ray Microanalysis (SEM-EDS), Linear Polarisation curves, (LP) Electrochemical Impedance Spectroscopy (EIS) and X-ray Photoelectron Spectroscopy (XPS).

\section{Materials and Methods}

Samples of the AA2024-T3 Al-Cu alloy, of $80 \mathrm{~mm} \times 25 \mathrm{~mm} \times 4 \mathrm{~mm}$ in size, were prepared. The composition of this alloy, in percentage by mass, is shown in Table 1 .

Table 1. AA2024-T3 chemical composition (wt. \%).

\begin{tabular}{ccccccccc}
\hline $\mathbf{S i}$ & $\mathbf{F e}$ & $\mathbf{C u}$ & $\mathbf{M n}$ & $\mathbf{M g}$ & $\mathbf{C r}$ & $\mathbf{Z n}$ & $\mathbf{T i}$ & $\mathbf{A l}$ \\
\hline 0.07 & 0.20 & 4.44 & 0.58 & 1.80 & 0.10 & 0.25 & 0.026 & 93.00 \\
\hline
\end{tabular}

Before the pretreatments, specimens were rinsed with acetone in order to remove adhesive rests coming from a plastic protective film and ink residues. As schematized in Figure 1, two different pretreatments (encoded here as Pretreatment 1 and 2), were carried out following the specification I+D-P-072:

Pretreatment 1 ( 2 consecutive steps): (i) 7 min stirring alkaline cleaning at $55{ }^{\circ} \mathrm{C}$ in 20 vol. \% Turco $6849(\mathrm{pH}=10.9),+\left(\right.$ ii) $10 \mathrm{~min}$ stirring alkaline degreasing at $50{ }^{\circ} \mathrm{C}$ in $40 \mathrm{~g} / \mathrm{L}$ Turco $4215 \mathrm{NC}-\mathrm{LT}$ $(\mathrm{pH}=8.9)$.

Pretreatment 2 ( 3 consecutive steps): (i) 7 min stirring alkaline cleaning at $55{ }^{\circ} \mathrm{C}$ in 20 vol. $\%$ Turco $6849(\mathrm{pH}=10.9),+$ (ii) $10 \mathrm{~min}$ stirring alkaline degreasing at $50{ }^{\circ} \mathrm{C}$ in $40 \mathrm{~g} / \mathrm{L}$ Turco $4215 \mathrm{NC}-\mathrm{LT}$ $(\mathrm{pH}=8.9),+$ (iii) $5 \mathrm{~min}$ without stirring acid cleaning at room temperature in $220 \mathrm{~g} / \mathrm{L}$ Smut Go NC $(\mathrm{pH}=1.2)$. 
Turco 6849, 4215 NC-LT and Smut Go NC were supplied by Henkel Ibérica, S.A., (Barcelona, Spain). Between each step the samples were rinsed and immersed during 3 min in deionized water with a $\mathrm{pH}$ of 5.6 and a resistivity of $15 \mathrm{M} \Omega$. According to the preparation steps, the samples have been codified as Not Treated, Pretreated 1 and Pretreated 2.

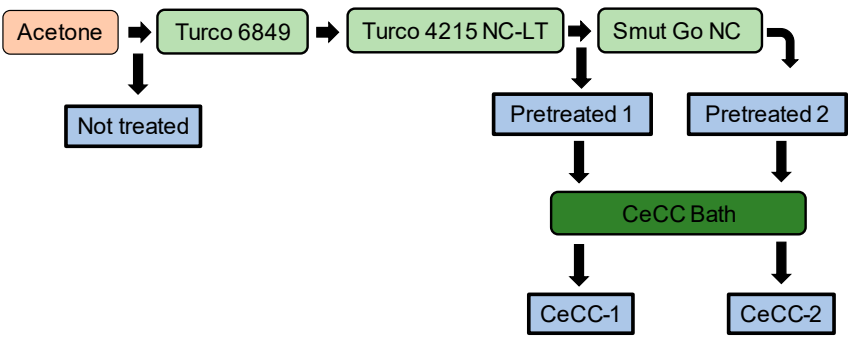

Figure 1. Sample preparation workflow.

CeCC was deposited after Pretreatments 1 and 2. The coating deposition took place in aqueous solution containing $35 \mathrm{mM} \mathrm{CeCl} \cdot 7 \mathrm{H}_{2} \mathrm{O}$ (supplied by Alfa Aesar, Karlsruhe, Germany) and $15 \mathrm{~mL} / \mathrm{L}$ $\mathrm{H}_{2} \mathrm{O}_{2} 30$ vol. \% (supplied by Panreac Química S.L.U., Barcelona, Spain), at $50{ }^{\circ} \mathrm{C}$ during $15 \mathrm{~min}$. The $\mathrm{pH}$ value was adjusted to 1.9 employing $1 \mathrm{M} \mathrm{HCl}$. The samples coated after Pretreatments 1 and 2 have been labelled as CeCC-1 and CeCC-2, respectively.

The surface appearance and composition of the samples were studied by scanning electron microscopy (SEM) (Hitachi, Tokio, Japan) at a voltage of 10 or $15 \mathrm{kV}$ and energy-dispersive X-ray analysis (EDX) (Bruker, Billerica, MA, USA) at a voltage of $15 \mathrm{kV}$ using a Hitachi SU 1510 microscope.

Potentionynamic linear polarisation (LP) and electrochemical impedance spectroscopy (EIS) measurements were conducted in three-electrode cells, making use of a PGSTAT302N potentiostat with frequency response analyzer (FRA) (Metrohm Autolab B.V., Utrecht, The Netherlands) controlled by the software NOVA 2.1.2. An Ag/ AgCl double junction electrode from Metrohm (0.207 V/SHE, 25 ${ }^{\circ} \mathrm{C}$ ) was employed as the reference electrode. The counter electrode was made of graphite for the LP and of platinized titanium for the EIS. The exposed surface of the working electrode was $1 \mathrm{~cm}^{2}$.

Previously to the LP the open circuit potential (OCP) was measured for one hour (this time was experimentally observed to reach potential stabilisation), being the average potential of the last $5 \mathrm{~s}$ the value adopted as corrosion potential ( $\left.E_{\text {corr }}\right)$. LP were carried out from $-0.025 \mathrm{~V}$ to $1 \mathrm{~V}$ vs. $E_{\text {corr }}$ in samples without CeCC and from $-0.25 \mathrm{~V}$ to $1 \mathrm{~V}$ in CeCC samples, at a rate of $0.17 \mathrm{mV} / \mathrm{s}$. The electrochemical activities of the samples were analysed based on the value of polarisation resistance $\left(R_{\mathrm{p}}\right)$ calculated through the Stern-Geary equation [26].

The frequency range of the impedance spectrum studied with EIS measurements corresponds to that in which the responses associated with the alloy phases and the passive film can be identified. It has been established that this range lies between $10^{-2}-10^{5} \mathrm{~Hz}$ [27]. The amplitude selected was $10 \mathrm{mV}$.

X-ray photoelectron spectroscopy (XPS) studies were carried out in a XPS spectrometer, Kratos AXIS Ultra DLD (Kratos Analytical Ltd., Manchester, UK). Samples were successively placed into the vacuum chamber of the spectrometer. Spectra were recorded with monochromatic Al K $\alpha$ radiation $(1486.6 \mathrm{eV})$ with a selected X-ray power of $150 \mathrm{~W}$. Surface charging effects were compensated by using the kratos coaxial neutralization system. The spectrometer was operated in the constant Analyzer Energy mode, with pass energy of $160 \mathrm{eV}$ for low resolution and wide range survey spectra, and $20 \mathrm{eV}$ for high resolution and narrow core level spectra. XPS spectra were treated with the software CasaXPS version 2.3.18PR1.0 (Casa Software Ltd., Cheshire, UK). 


\section{Results}

\subsection{Surface Morphology and Microstructure of Uncoated Samples}

The microstructure analysis performed by SEM-EDX has revealed the presence of the main types of intermetallic particles of the alloy AA2024-T3, whose compositions are comparable with those described by Campestrini et al. [28] for alloys of the same group. In the studies reported in References [1-7], the atomic percentages of the alloying elements that comprise each intermetallic particle have been determined. Firstly, round shaped particles with a diameter of 5-8 $\mu$ m have been identified, with a composition of $\mathrm{Al}-\mathrm{Cu}-\mathrm{Mg}$, commonly known as S-Phase, Figure 2 (see white arrows). Although a stoichiometry of $\mathrm{Al}_{2} \mathrm{CuMg}$ has been classically assigned to this type of phase, it is in fact a mixture of $\mathrm{Al}_{2} \mathrm{CuMg}$ and small quantities of $\mathrm{Al}_{2} \mathrm{Cu}$ ( $\theta$-Phase) $[6,7,29,30]$. In the present work, the mixture $\mathrm{Al}_{2} \mathrm{CuMg} / \mathrm{Al}_{2} \mathrm{Cu}$ is referred as $\mathrm{Al}(\mathrm{Cu}, \mathrm{Mg})$. A second group of particles of irregular appearance, whose dimensions range from a few micrometres up to $15 \mu \mathrm{m}$, are composed of Al-Cu-Mn-Fe-Si or Al-Cu-Fe-Mn; these are present on the surface as both isolated particles and clusters or clumps of several particles, Figure 2 (see black arrows). The stoichiometry of this second type is more difficult to assign [4,5], but it has been defined as Al-Cu-Mn-Fe-(Si).
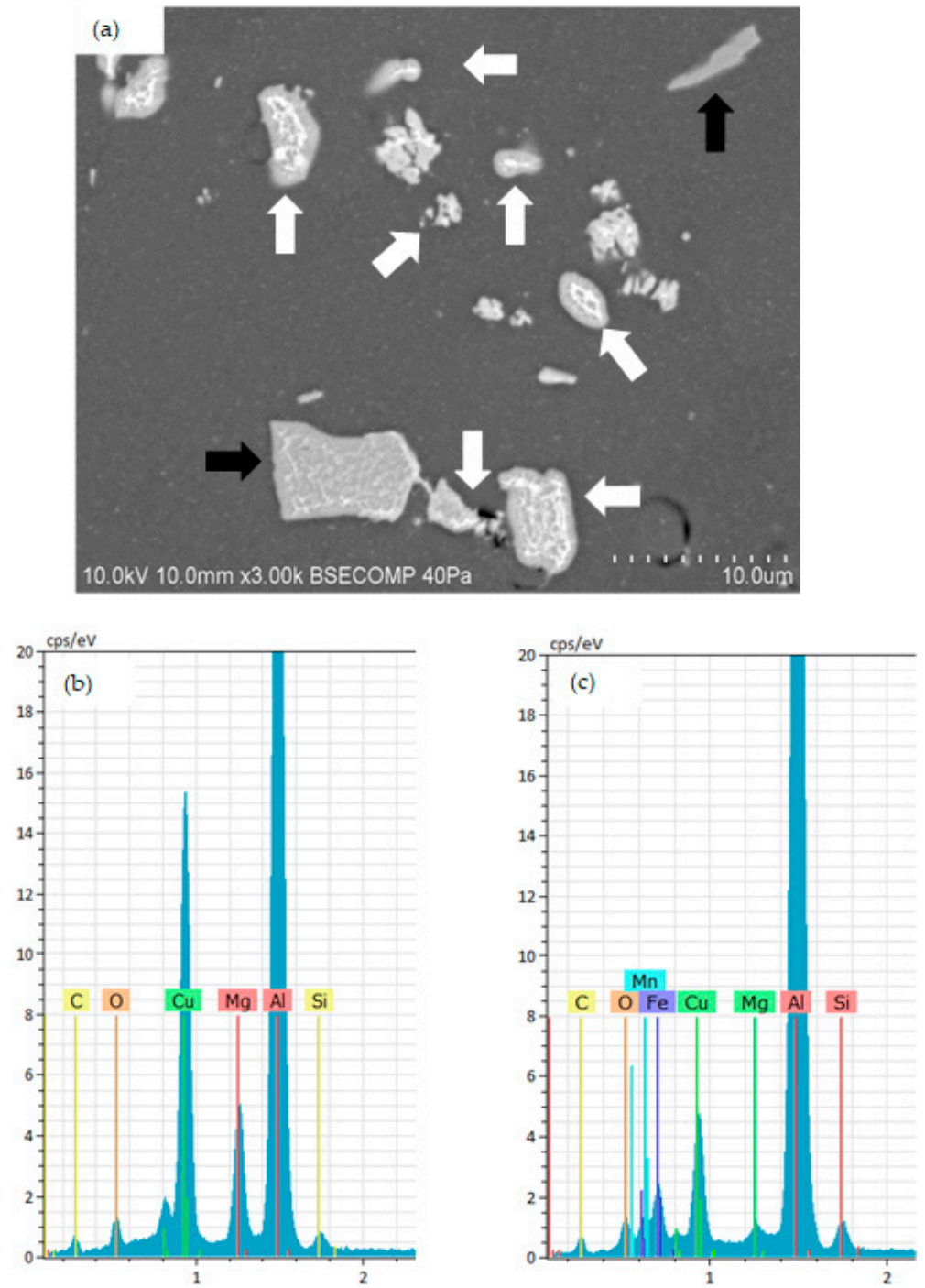

Figure 2. (a) Scanning electron microscopy (SEM) image of the main phases identified in alloy AA2024-T3; (b) Energy-dispersive X-ray analysis (EDX) spectrum of $\mathrm{Al}(\mathrm{Cu}, \mathrm{Mg})$ particle (white arrows); (c) EDX spectrum of Al-Cu-Fe-Mn-(Si) particle (black arrows). 
Figure 3a depicts SEM image corresponding to the same area shown in Figure 2 after being treated with Pretreatment 1. Major surface morphological changes were not observed with respect to those non-treated (Figure 2). Al(Cu,Mg) and Al-Cu-Mn-Fe-(Si) phases do not show signs of attacks. The EDX analysis of the phases, Figure $3 b, c$, confirms that there have not been apparent compositional changes.
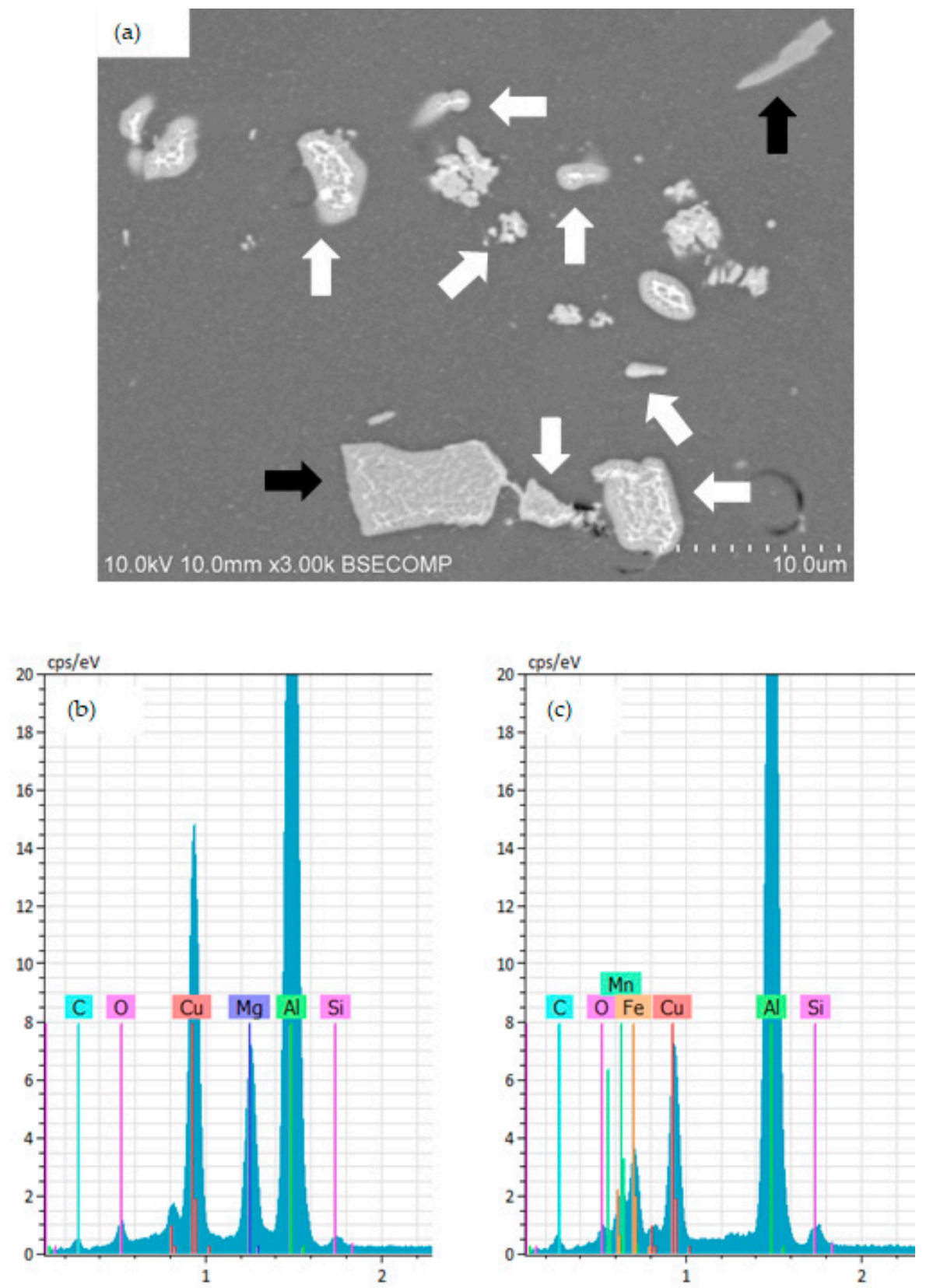

Figure 3. (a) SEM image of the main phases identified in alloy AA2024-T3 after Pretreatment 1; (b) EDX spectrum of $\mathrm{Al}(\mathrm{CuMg}$ ) particle (white arrows); (c) EDX spectrum of $\mathrm{Al}-\mathrm{Cu}-\mathrm{Fe}-\mathrm{Mn}$-(Si) particle (black arrows).

Conversely, some intermetallic particles have been removed after Pretreatment 2, giving rise to cavities that appear in positions in which there were $\mathrm{Al}(\mathrm{Cu}, \mathrm{Mg})$ phases, see white arrows in Figure $4 \mathrm{a}$. In other cases, $\mathrm{Al}(\mathrm{Cu}, \mathrm{Mg})$ particles with sponge appearance after being etched still remain, marked with red arrows in Figure $4 \mathrm{a}$. Microanalysis of these particles, as the one included in Figure $4 \mathrm{~b}$, reveal the absence of $\mathrm{Mg}$ signal, the increase of $\mathrm{Cu}$ peak and the reduction of $\mathrm{Al}$ peak. In contrast, 
Al-Cu-Mn-Fe-(Si) intermetallics were not affected and are still visible in Figure 4a, marked with black arrows, without evidences of compositional changes, Figure 4c.
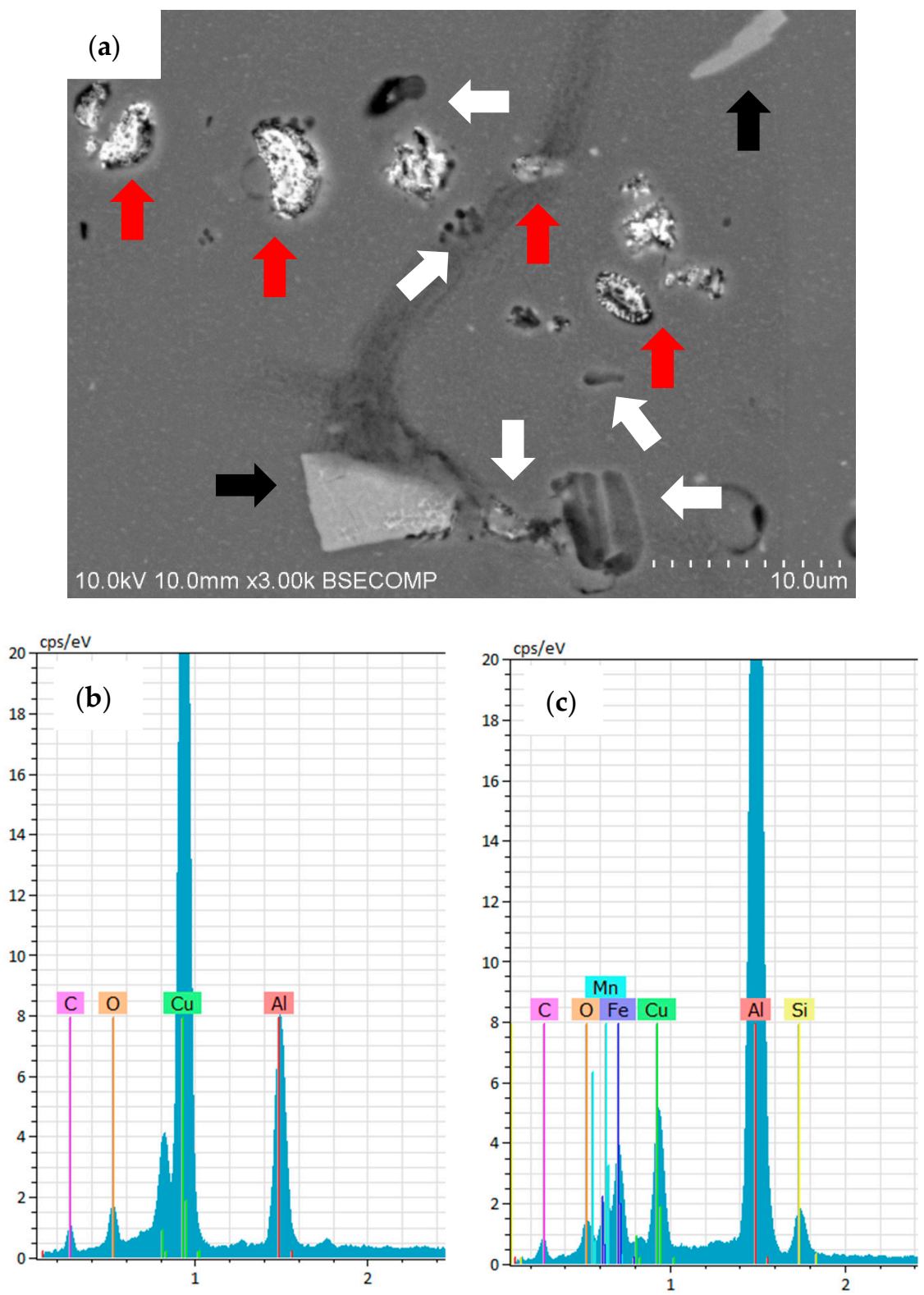

Figure 4. (a) SEM image of the main phases identified in alloy AA2024-T3 after Pretreatment 2; (b) EDX spectrum of sponge-like $\mathrm{Al}(\mathrm{Cu}, \mathrm{Mg})$ particle (white arrows); (c) EDX spectrum of Al-Cu-Fe-Mn-(Si) particle (black arrows).

In order to obtain more detailed information, a semi-quantitative analysis of the EDX spectra acquired on a group of intermetallic particles was performed in samples Not Treated, after Pretreatment 1 and after Pretreatment 2. The averaged results of the analysis of 3 representative particles are included in Figure 5. 
(a)

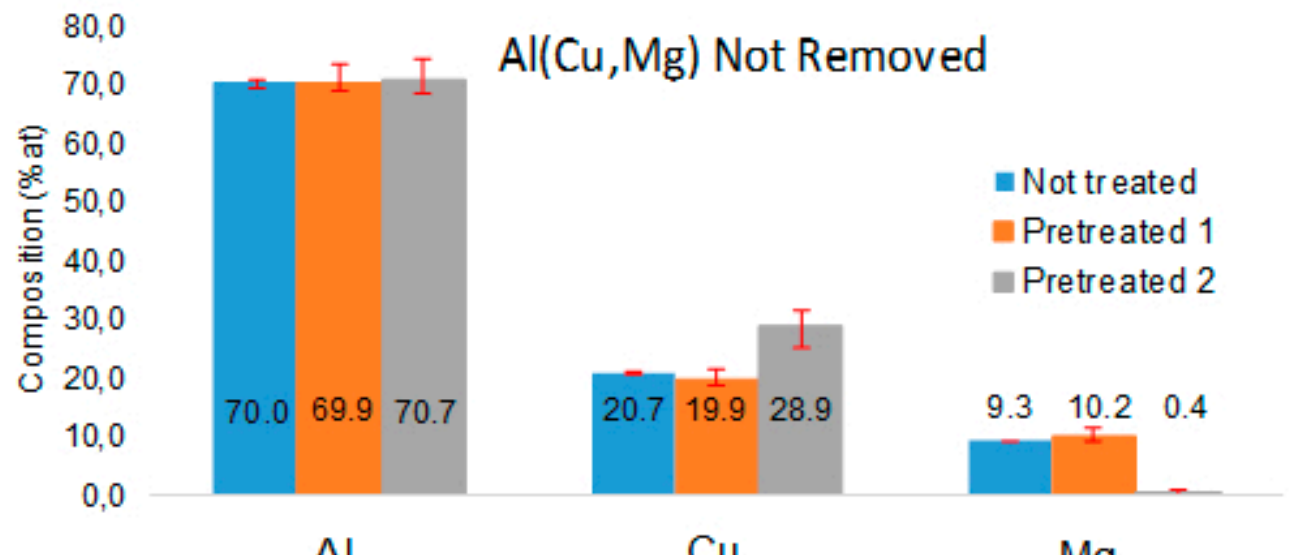

(b)

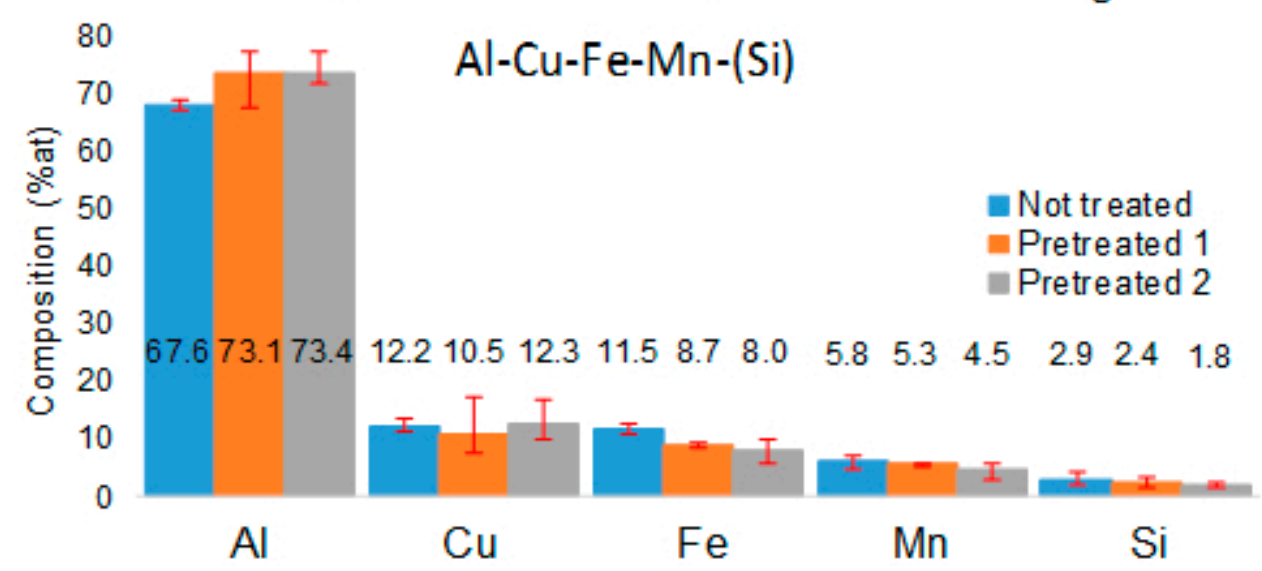

(c) $\quad 100,0$

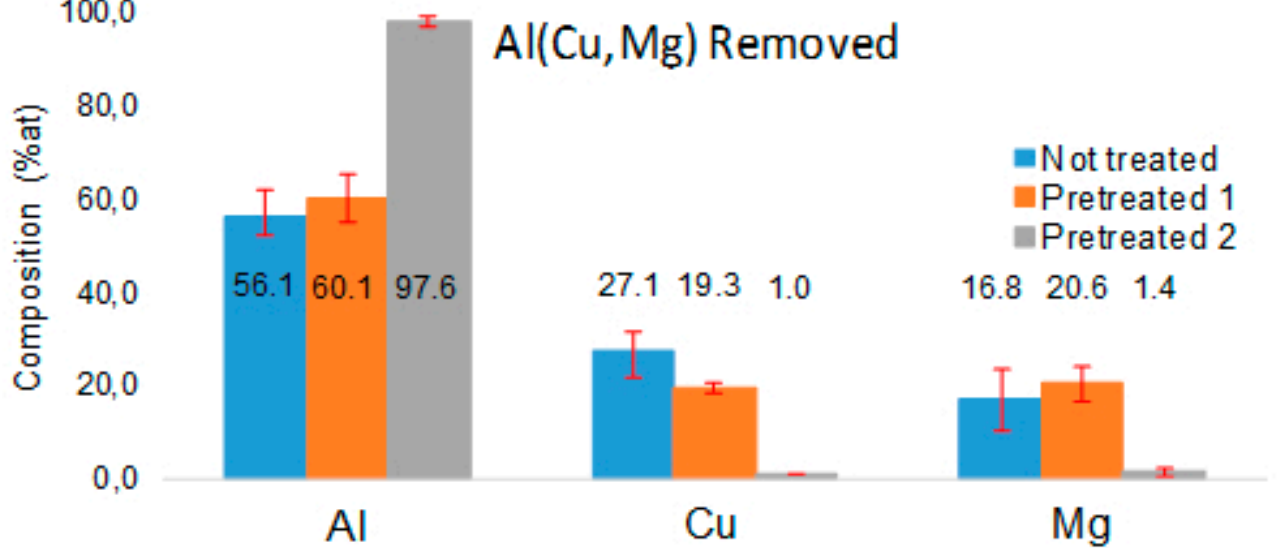

Figure 5. Bar plots of semi-quantitative analysis of (a) $\mathrm{Al}(\mathrm{Cu}, \mathrm{Mg})$ not removed, (b) $\mathrm{Al}-\mathrm{Cu}-\mathrm{Fe}-\mathrm{Mn}-(\mathrm{Si})$ and (c) $\mathrm{Al}(\mathrm{Cu}, \mathrm{Mg})$ removed.

Quantification has been calculated assigning 100\% to the sum of the percentages found per elements of each phase. In samples after Pretreatment 1, almost no difference in atomic \% was observed in the whole set of data. Therefore, alkaline degreasing and alkaline cleaning do not affect the $\mathrm{Al}(\mathrm{Cu}, \mathrm{Mg})$ neither $\mathrm{Al}-\mathrm{Cu}-\mathrm{Mn}-\mathrm{Fe}-(\mathrm{Si})$ morphologies and compositions, Figures $2 \mathrm{a}$ and $3 \mathrm{a}$ (see white arrows). In samples after Pretreatment 2, significant changes in the atomic \% were not observed in the case of $\mathrm{Al}-\mathrm{Cu}-\mathrm{Fe}-\mathrm{Mn}-(\mathrm{Si})$, black arrows in Figure $4 \mathrm{~b}$. However, intermetallics $\mathrm{Al}(\mathrm{Cu}, \mathrm{Mg})$ were attacked. Two different effects were observed in the atomic \%. Firstly, $\mathrm{Al}(\mathrm{Cu}, \mathrm{Mg})$ were detached, white arrows in Figure $4 a$, since the analysis on the place where they were, provide almost $100 \%$ of aluminium, confirming that EDX spectra was acquired on the aluminium matrix. Secondly, the quantification 
of $\mathrm{Al}(\mathrm{Cu}, \mathrm{Mg})$ with a sponge appearance indicates that the magnesium was reduced to almost zero, with the copper content being increased, and the aluminium remaining unaltered.

\subsection{Surface Morphology and Microstructure of Coated Samples}

Optical images at $72 \times$ of CeCC-1 and CeCC-2 samples, included in Figure 6, allow us to observe two different areas: yellow zones characteristic of cerium coating and grey areas where no coating or a very thin layer is expected to be found. It is clear that sample CeCC-1 has a higher uniformity and coverage than sample CeCC-2.
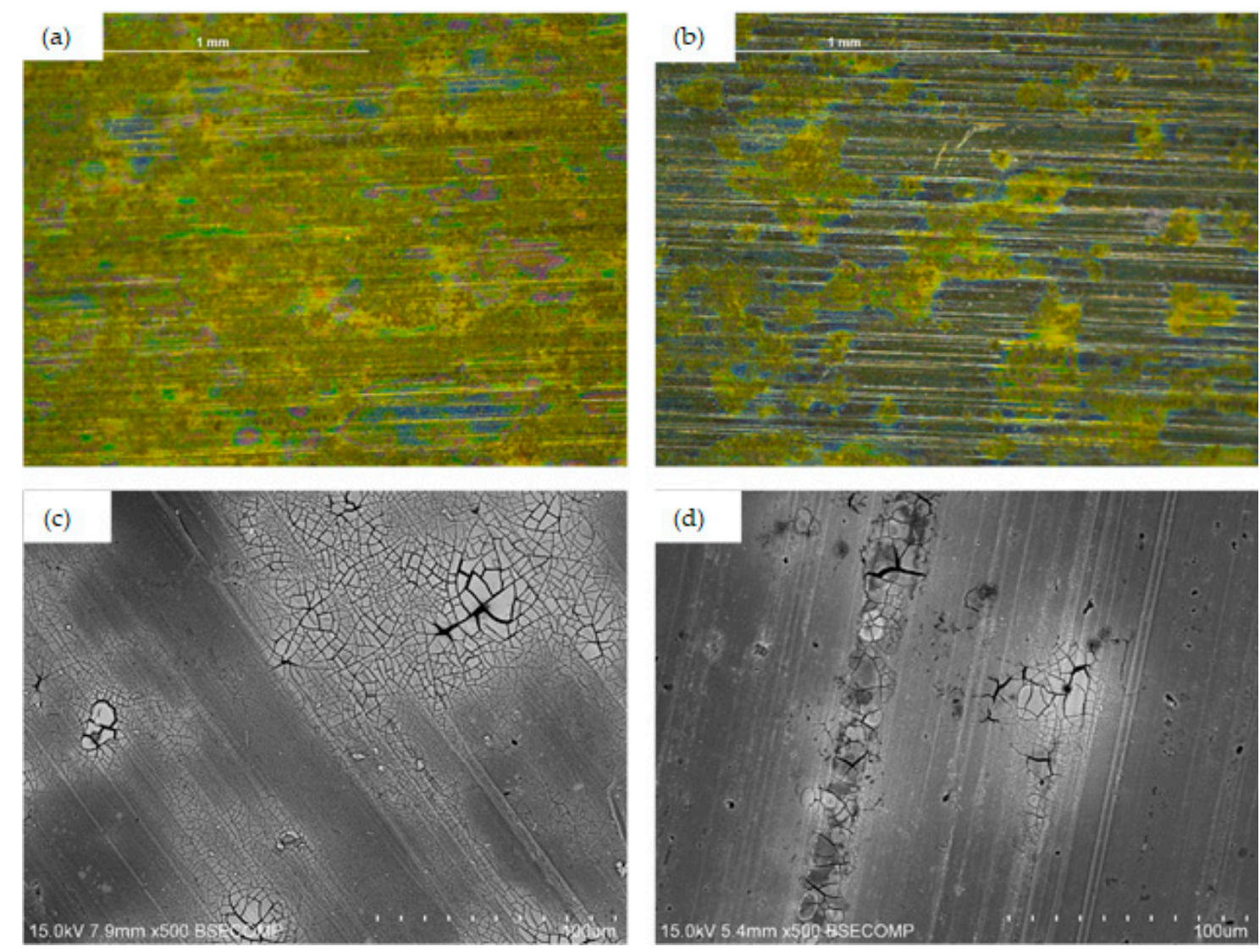

Figure 6. Surface morphology of samples. Optical images at $72 \times$ of (a) CeCC-1 and (b) CeCC-2. SEM images at $500 \times$ of $(\mathbf{c})$ CeCC-1 and (d) CeCC-2.

SEM images shown in Figure 6 are representative areas acquired on samples CeCC-1 (Figure 6c) and CeCC-2 (Figure 6d) using backscattered electrons mode. EDX analysis confirmed that there are three main features in the two kind of samples: areas with the characteristic texture of dried-mud cerium coating, cerium agglomerates over intermetallics and areas apparently free of coating or, at least, with a very thin layer. In addition, it is found that the deposition of the coating proceeds preferentially along lines parallel to rolling marks of the alloy in sample CeCC-2, as observed in Figure 6d.

Figure 7 shows a SEM image at $2500 \times$ and two punctual EDS spectra of an agglomerate of cerium in $\mathrm{CeCC}-1$ sample. The EDX results unveil the presence of $\mathrm{Al}, \mathrm{Cu}$ and $\mathrm{Mg}$ along with $\mathrm{Ce}$ and $\mathrm{O}$ in the center of the agglomerate (red arrow in Figure 7a). Meanwhile, only Ce and $\mathrm{O}$ are present in the surrounding area. These results are characteristics of cerium coating formation over $\mathrm{Al}(\mathrm{Cu}, \mathrm{Mg}) \mathrm{phases}$ and they are referred to as "cerium island" in the literature [16,31,32]. The number of cerium island texture was higher in the sample CeCC-1. 

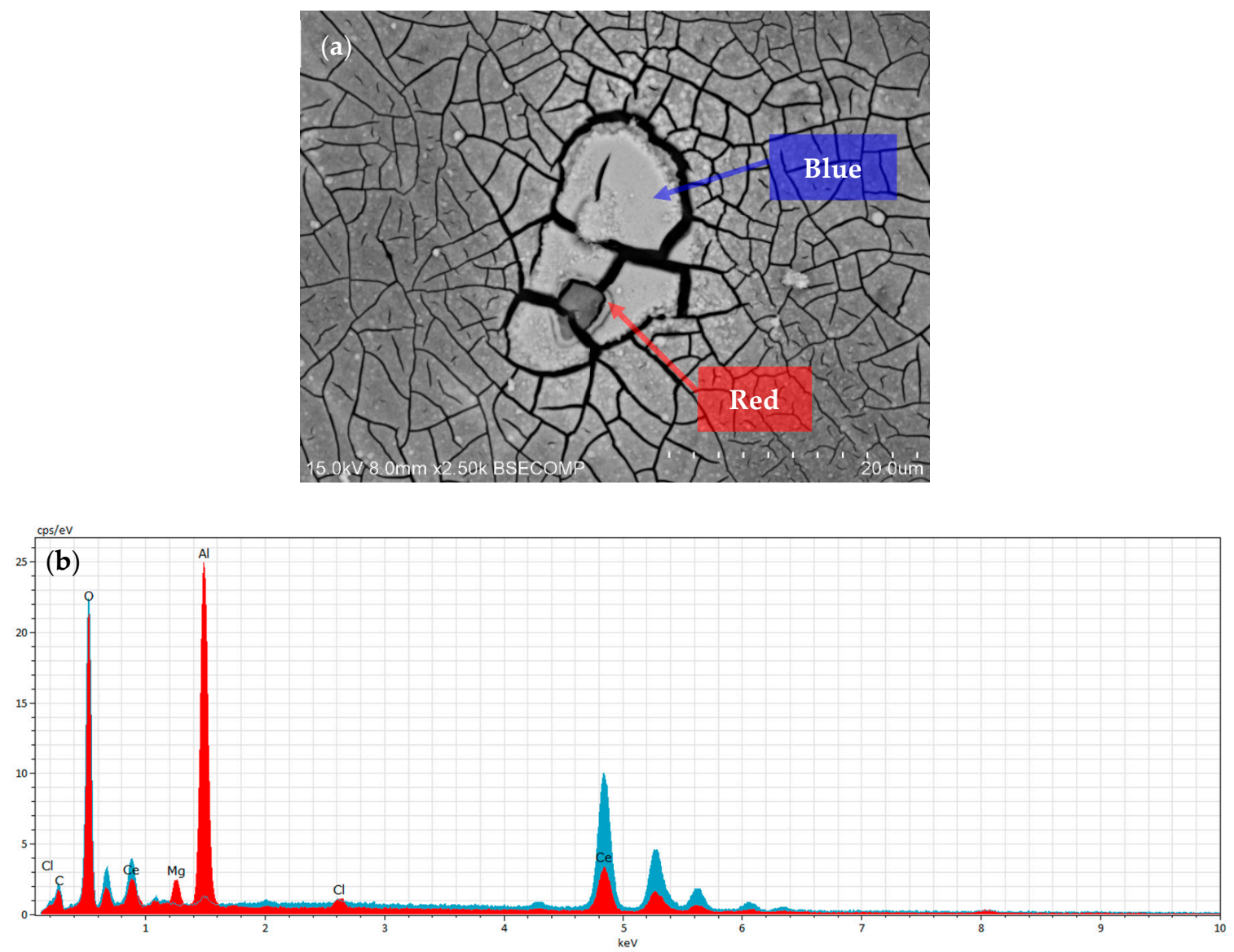

Figure 7. (a) SEM image of a cerium island in sample CeCC-1. (b) EDX spectra in the central area (red) and in the surrounding area (blue).

However, it was not possible to detect by EDX microanalysis cerium agglomerates containing $\mathrm{Fe}, \mathrm{Mn}$ and $\mathrm{Si}$ to confirm the deposition over Al-Cu-Fe-Mn-(Si) intermetallics. This is thought to be associated to the technique limitations, as the Ce layer developed in these particles are relatively thick. In order to verify that $\mathrm{Ce}$ can also deposit in these $\mathrm{Al}-\mathrm{Cu}-\mathrm{Fe}-\mathrm{Mn}-(\mathrm{Si})$ intermetallic particles, additional samples (encoded as $\mathrm{CeCC}-1^{\prime}$ ) were prepared and studied in which CeCC coating was deposited during only $3 \mathrm{~min}$ (instead of the $15 \mathrm{~min}$ used in CeCC-1). Figure 8 includes two SEM images at 1400× of samples Not Treated and a sample CeCC-1' deposited for $3 \mathrm{~min}$ and two punctual EDX spectra of the structures surrounded by discontinues lines. Spectrum in Figure 8c evidences the fact that the structure studied in Figure 8a) is an Al-Cu-Fe-Mn-(Si) phase. In Figure 8b it can be observed how the $\mathrm{CeCC}$ is deposited preferentially on the structure $\mathrm{Al}-\mathrm{Cu}-\mathrm{Fe}-\mathrm{Mn}-(\mathrm{Si})$. 

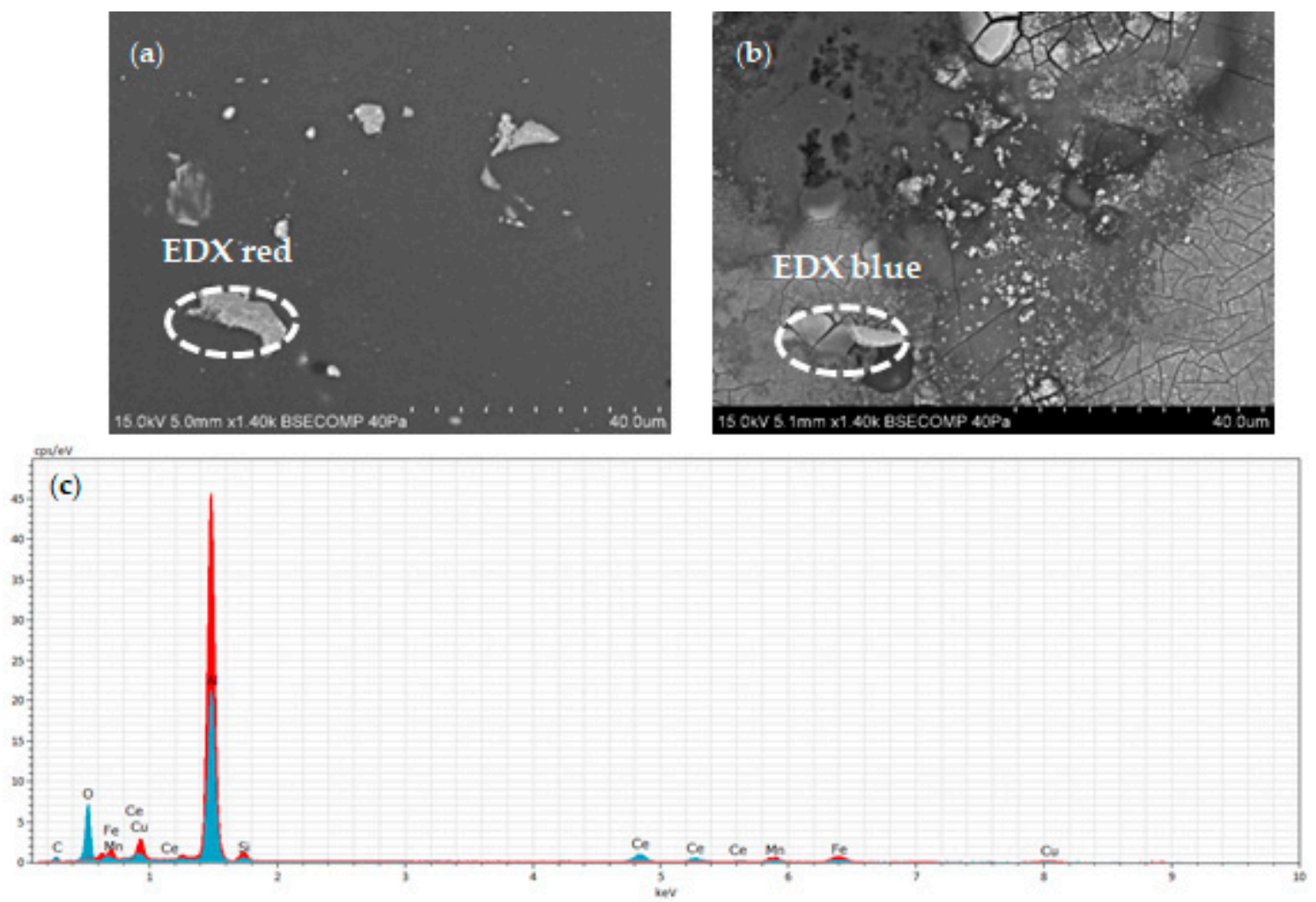

Figure 8. SEM image of Al-Cu-Fe-Mn-(Si) in a CeCC-1' sample (a) before and (b) after a deposition of cerium during $3 \mathrm{~min}$. (c) EDX spectra acquired over the particle marked in (a) and (b).

\subsection{Electrochemical Characterisation by LP of Uncoated and Coated Samples}

LP measurements were carried out to assess the electrochemical changes provoked by the pretreatments on the surface of the alloy. Figure 9 presents LP curves for samples Not Treated, Pretreated 1, Pretreated 2, CeCC-1 and CeCC-2 in aerated solution of $0.59 \mathrm{M} \mathrm{NaCl} . R_{\mathrm{p}}$ values given in Table 2 are obtained from evaluation of the potentiodynamic polarisation curves.

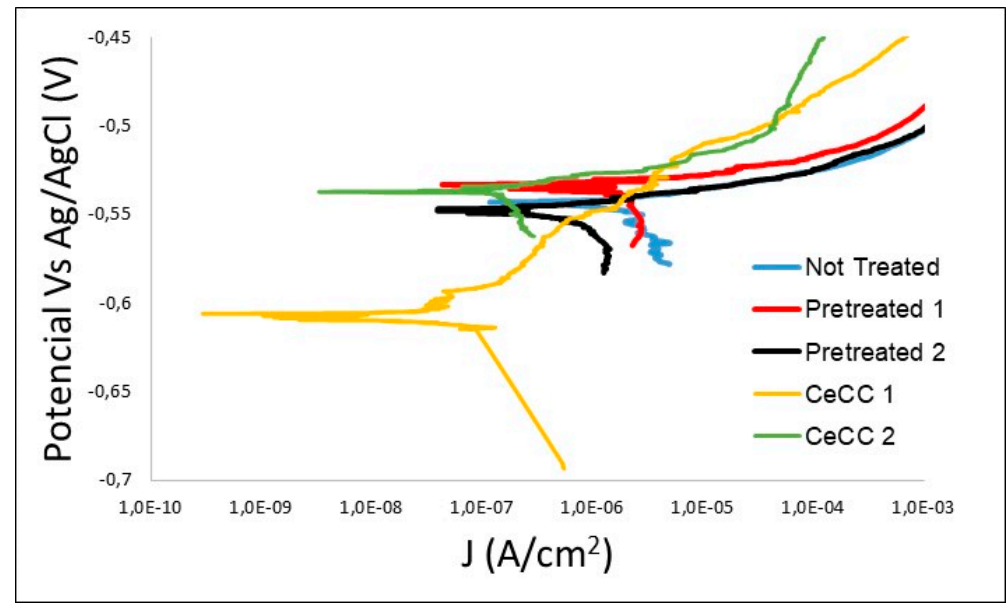

Figure 9. Potentiodynamic linear polarisation (LP) curves of samples Not Treated, Pretreated 1, Pretreated 2, CeCC-1 and CeCC-2 immersed in $\mathrm{NaCl} 0.59 \mathrm{M}$.

Due to the absence of coating, all samples suffer from active corrosion phenomena in the $\mathrm{NaCl}$ solution, with fluctuating corrosion potential $\left(E_{\text {corr }}\right)$ around -0.53 and $-0.57 \mathrm{~V} \mathrm{vs.} \mathrm{Ag} / \mathrm{AgCl}(0.207 \mathrm{~V} /$ SHE). The pitting nucleation potential $\left(E_{\mathrm{np}}\right)$ are very close to $E_{\mathrm{corr}}$ so as for potentials slightly higher than $E_{\text {corr }}$ the current density increases sharply due to the intense anodic activity taking place in 
the system. The $R_{\mathrm{p}}$ values of samples Not Treated and Pretreated 1 are of the same order, 955 and $1068 \Omega \cdot \mathrm{cm}^{2}$, demonstrating, hence, the small difference between the surfaces of non-treated samples and the latter.

Table 2. Electrochemical parameters calculated from LP curves in Figure 9.

\begin{tabular}{cccccc}
\hline Electrochemical Parameters & Not Treated & Pretreated 1 & Pretreated 2 & CeCC-1 & CeCC-2 \\
\hline$E_{\text {corr }}(\mathrm{V})$ & -0.543 & -0.535 & -0.549 & -0.609 & -0.537 \\
$E_{\mathrm{np}}(\mathrm{V})$ & -0.543 & -0.535 & -0.549 & -0.520 & -0.520 \\
$J_{\text {corr }}\left(\mathrm{A} \cdot \mathrm{cm}^{-2}\right)$ & $2.70 \times 10^{-5}$ & $2.45 \times 10^{-5}$ & $4.07 \times 10^{-6}$ & $2.1 \times 10^{-7}$ & $1.31 \times 10^{-6}$ \\
$R_{\mathrm{p}}\left(\Omega \cdot \mathrm{cm}^{2}\right)$ & 955 & 1068 & 6407 & $1.23 \times 10^{5}$ & $1.99 \times 10^{4}$ \\
$R^{2}$ & 0.830 & 0.766 & 0.872 & 0.854 & 0.867 \\
\hline
\end{tabular}

On the contrary, as can be observed in Figure 9, the effect of the Pretreatment 2 causes a displacement of the cathodic branch toward lower current densities, bringing about a reduction in the activity of the system. The $R_{\mathrm{p}}$ of sample Pretreated 2 grew up to $6407 \Omega \cdot \mathrm{cm}^{2}$.

The linear polarisation curve of CeCC-1 sample showed in Figure 9 displays a corrosion potential of $-0.609 \mathrm{~V}$ approximately, lower than the sample Not Treated, that it is around $-0.543 \mathrm{~V}$. CeCC- 1 also has an incipient passive region in the anodic branch from $-0.609 \mathrm{~V}\left(E_{\text {corr }}\right)$ up to $-0.520 \mathrm{~V}\left(E_{\mathrm{np}}\right)$.

On its part, $E_{\text {corr }}$ of CeCC-2 keeps very close to $E_{\text {corr }}$ of sample Not Treated and a slightly displaced to noble potential from Pretreated 2 samples. Furthermore, it can barely be distinguished a very small passive region up to $E_{\mathrm{np}}=-0.520 \mathrm{~V}$. It is noticeable that $E_{\mathrm{np}}$ of both coated samples have displaced upwards to $-0.520 \mathrm{~V}$ compared with their corresponding uncoated samples Pretreated 1 and Pretreated 2.

All CeCC coated samples give curves with cathodic branches shifted 1 or 2 orders of magnitude to lower current densities than uncoated ones, regardless of the pretreatments applied. Notwithstanding, it can be observed in Table 2 that the sample CeCC- 1 has lower $J_{\text {corr }}$ and higher $R_{\mathrm{p}}$ than CeCC-2. The differences are roughly one order of magnitude for both magnitudes. Both coated samples showed clearly improved corrosion protection, their $R_{\mathrm{p}}$ reaching $1.23 \times 10^{5}$ and $1.99 \times 10^{4} \Omega \cdot \mathrm{cm}^{2}$ for CeCC-1 and CeCC-2, respectively.

\subsection{Electrochemical Characterisation by EIS of Coated Samples}

Figure 10 presents the Nyquist diagrams obtained from EIS tests acquired in a solution of $0.59 \mathrm{M}$ $\mathrm{NaCl}$ in samples CeCC-1 and CeCC-2. Only one depressed and not fully completed semicircle can be found in each sample, being the semicircle of CeCC-1 higher than that of CeCC-2. The equivalent circuit employed (Randles Circuit) to fit them is shown in Figure 11, where $R_{\mathrm{S}}$ is the resistance of the solution, $R_{\mathrm{c}}$ and CPE are the resistance and the constant phase element (CPE) accounting for the whole coating system, including alumina and cerium compounds. The fitting results included in Table 3 are in good agreement with the Polarisation curve. $R_{\mathrm{c}}$ can be assumed to be an estimation of $R_{\mathrm{p}}$. Therefore, $R_{\mathrm{c}}$ in sample CeCC-1 is higher than CeCC-2, 19,500 and $12,000 \Omega \cdot \mathrm{cm}^{2}$ respectively. Despite the difference in $R_{\mathrm{c}}$ values is smaller than the difference of $R_{\mathrm{p}}$ calculated from polarisation curves, they are coherent in the sense of higher $R_{\mathrm{p}}$ and $R_{\mathrm{c}}$ values of CeCC-1 sample.

Table 3. Values of fitting analysis of the experimental EIS data employing the equivalent.

\begin{tabular}{ccc}
\hline Equivalents Circuit Elements & CeCC-1 & CeCC-2 \\
\hline$R_{\mathrm{e}}\left(\Omega \cdot \mathrm{cm}^{2}\right)$ & 23.5 & 20 \\
$R_{\mathrm{c}}\left(\Omega \cdot \mathrm{cm}^{2}\right)$ & 18,000 & 12,000 \\
$\mathrm{CPE}\left(\mu \Omega^{-1} \cdot \mathrm{S}^{n} \cdot \mathrm{cm}^{-2}\right)$ & 352 & 253 \\
$n$ & 0.840 & 0.861 \\
\hline
\end{tabular}




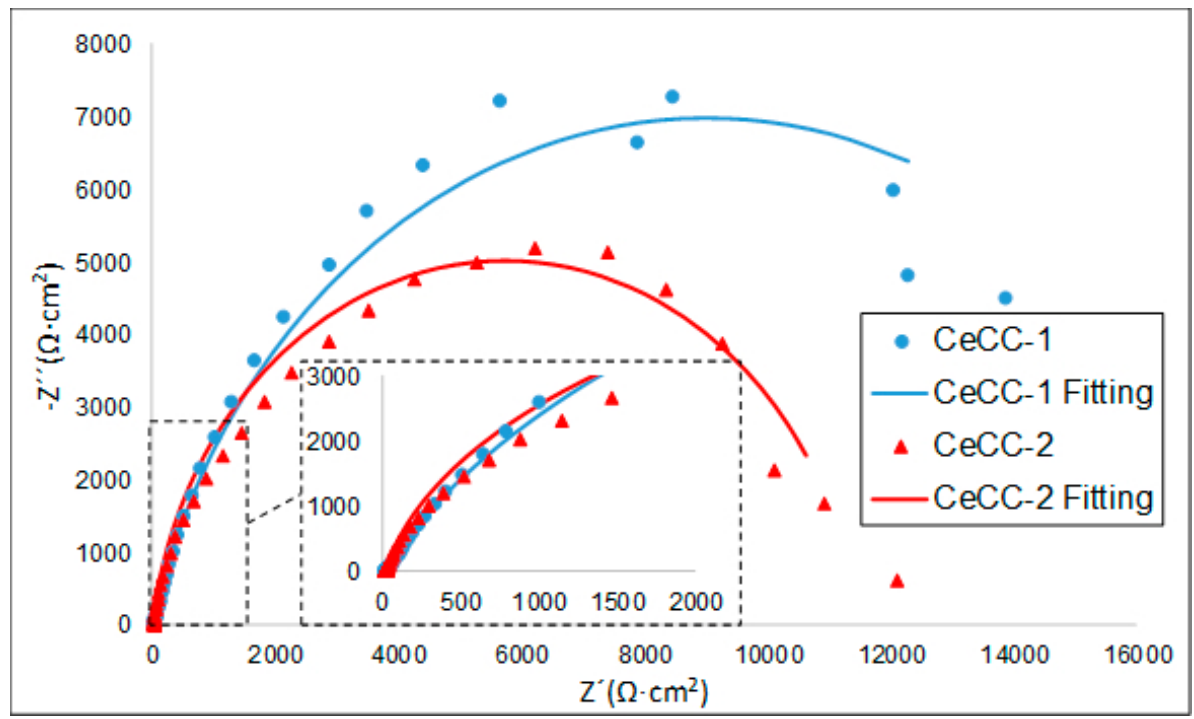

Figure 10. Nyquist impedance plots of CeCC-1, CeCC-2 and their fitting to the equivalent circuit of Figure 11.

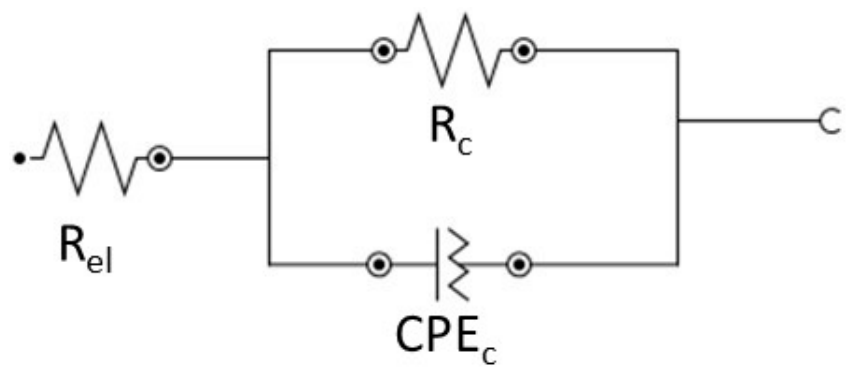

Figure 11. Equivalent circuit used for the analysis of electrochemical impedance spectroscopy (EIS) data.

\subsection{XPS Characterisation of Coated Samples}

The survey XPS spectra of samples CeCC-1 and CeCC-2 are presented in Figure 12. The main elements detected are $\mathrm{O}, \mathrm{Ce}, \mathrm{Al}, \mathrm{Cu}$ and $\mathrm{C}$. Table 4 shows the relative content of them calculated from survey spectra in Figure 12.

Table 4. Surface composition of samples CeCC-1 and CeCC-2 (at. \%).

\begin{tabular}{ccc}
\hline Signals & CeCC-1 & CeCC-2 \\
\hline O1s & 84.22 & 87.76 \\
Al2p & 9.75 & 9.25 \\
Ce3d & 5.98 & 2.79 \\
Cu2p & 0.05 & 0.20 \\
\hline
\end{tabular}

Figure 13 depicts the high resolution XPS spectra of Ce3d signals. This complex group of peaks comprises two cerium oxidation states, covalence hybridization effects and spin-orbit splitting. It consists of five doublets corresponding to the $3 \mathrm{~d}_{5 / 2}$ and $3 \mathrm{~d}_{3 / 2}$ components. Three doublets, labelled as $\mathrm{v}-\mathrm{u}, \mathrm{v}^{\prime \prime}-\mathrm{u}^{\prime \prime}$ and $\mathrm{v}^{\prime \prime \prime}-\mathrm{u}^{\prime \prime \prime}$, can be attributed to $C \mathrm{e}^{4+}$, whereas the other two doublets, $\mathrm{v}_{0}-\mathrm{u}_{0}$ and $\mathrm{v}^{\prime}-\mathrm{u}^{\prime}$, are due to $\mathrm{Ce}^{3+}$ [33-38]. Table 5 summarises the energy of these peaks for CeCC-1 and CeCC-2 samples. 

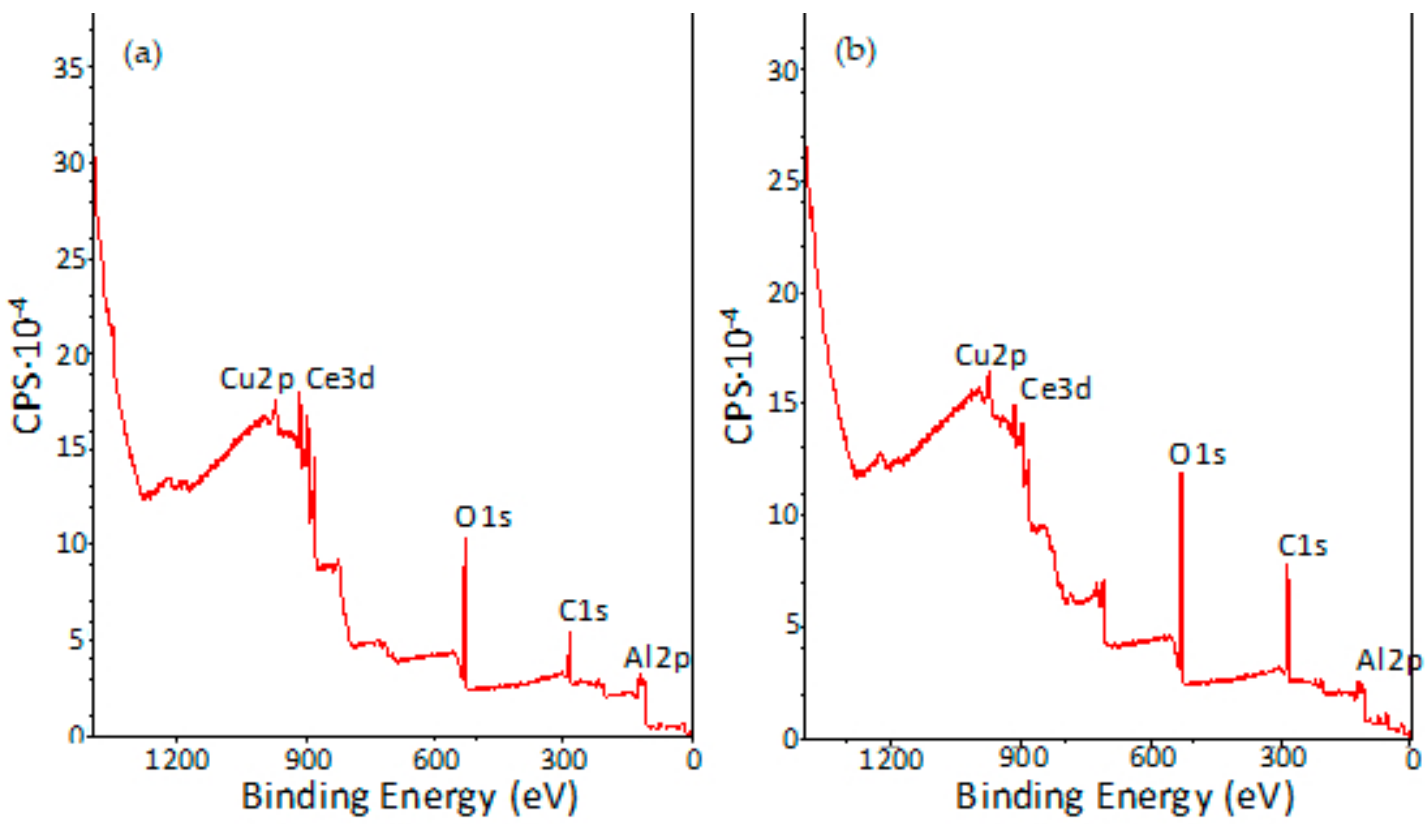

Figure 12. Survey X-ray photoelectron spectroscopy (XPS) spectra of (a) CeCC-1 and (b) CeCC-2.
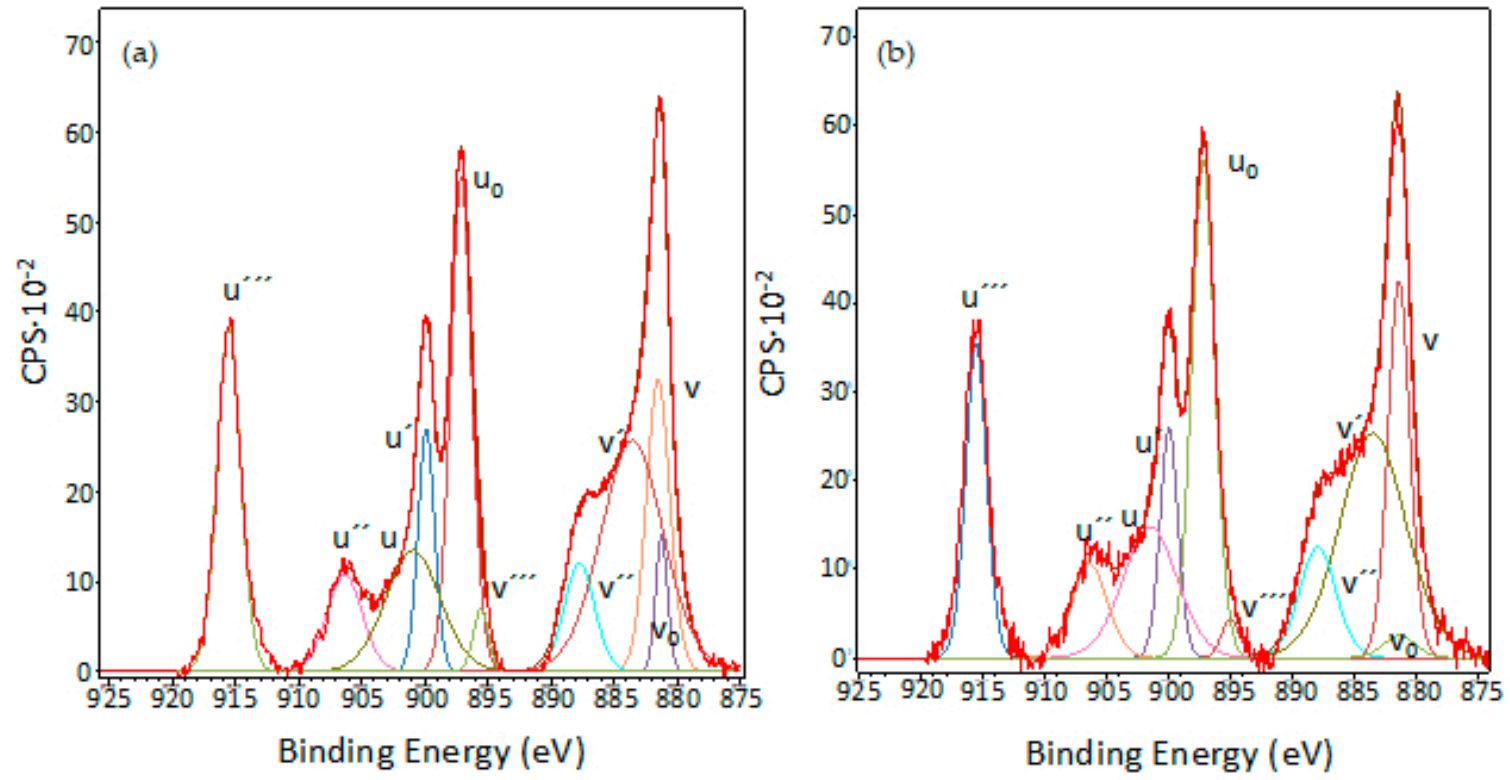

Figure 13. XPS spectra of Ce3d. (a) CeCC-1. (b) CeCC-2.

Table 5. Energy assigned to peaks of Ce3d signals $(\mathrm{eV})$.

\begin{tabular}{ccc}
\hline Signals & CeCC-1 & CeCC-2 \\
\hline \multicolumn{3}{c}{ Ce (IV) } \\
\hline $\mathrm{v}-\mathrm{u}$ & $881.6-901.3$ & $881.4-901.4$ \\
$\mathrm{v}^{\prime \prime}-\mathrm{u}^{\prime \prime}$ & $887.91-906.3$ & $887.9-906.6$ \\
$\mathrm{v}^{\prime \prime \prime}-\mathrm{u}^{\prime \prime \prime}$ & $895.6-915.6$ & $895.3-915.6$ \\
\hline \multicolumn{3}{|}{ Ce(III) } \\
\hline $\mathrm{v}_{0}-\mathrm{u}_{0}$ & $881.1-897.4$ & $881.1-897.3$ \\
$\mathrm{v}^{\prime}-\mathrm{u}^{\prime}$ & $883.6-901.0$ & $883.5-900.3$ \\
\hline
\end{tabular}


The $\mathrm{u}^{\prime \prime \prime}$ peak is isolated from the others and comes exclusively from $\mathrm{Ce}^{4+}$. Therefore, it has been studied by several authors as indicator of the ratio $\mathrm{Ce}^{4+} / \mathrm{Ce}^{3+}$ in the CeCC [33-38]. More specifically, the $\mathrm{u}^{\prime \prime \prime}$ peak allow the estimation of the $\mathrm{Ce}^{4+\%} \%$ through Equation (1), proposed by Shyu et al. [36].

$$
\mathrm{Ce}^{4+\%}=\frac{\mathrm{u}^{\prime \prime \prime} \%}{14} \times 100
$$

where $\mathrm{u}^{\prime \prime \prime} \%$ is percentage of $\mathrm{u}^{\prime \prime \prime}$ peak area with respect to the total Ce $3 \mathrm{~d}$ area. The Ce $\mathrm{e}^{4+\%}$ calculated for sample CeCC-1 and CeCC-2 are 107\% and 76\%. However, it is necessary to remark than the estimated error of this method is in the range of $10 \%$ [36].

High resolution XPS spectra of signal Al2p in samples CeCC-1 and CeCC-2 are presented in Figure 14. A first peak at around $75 \mathrm{eV}$ is related to Al-O group. At higher binding energy, there is a peak attributed to $\mathrm{Al} / \mathrm{O} / \mathrm{Ce}$ mixed chemical compounds, at approximately $76.9 \mathrm{eV}$ [35]. It is noticeable that the characteristic signal of Al-Al around $72.6 \mathrm{eV}$ was present in samples Pretreated 1 and Pretreated 2 (not shown) but it is not found after cerium coating treatment.
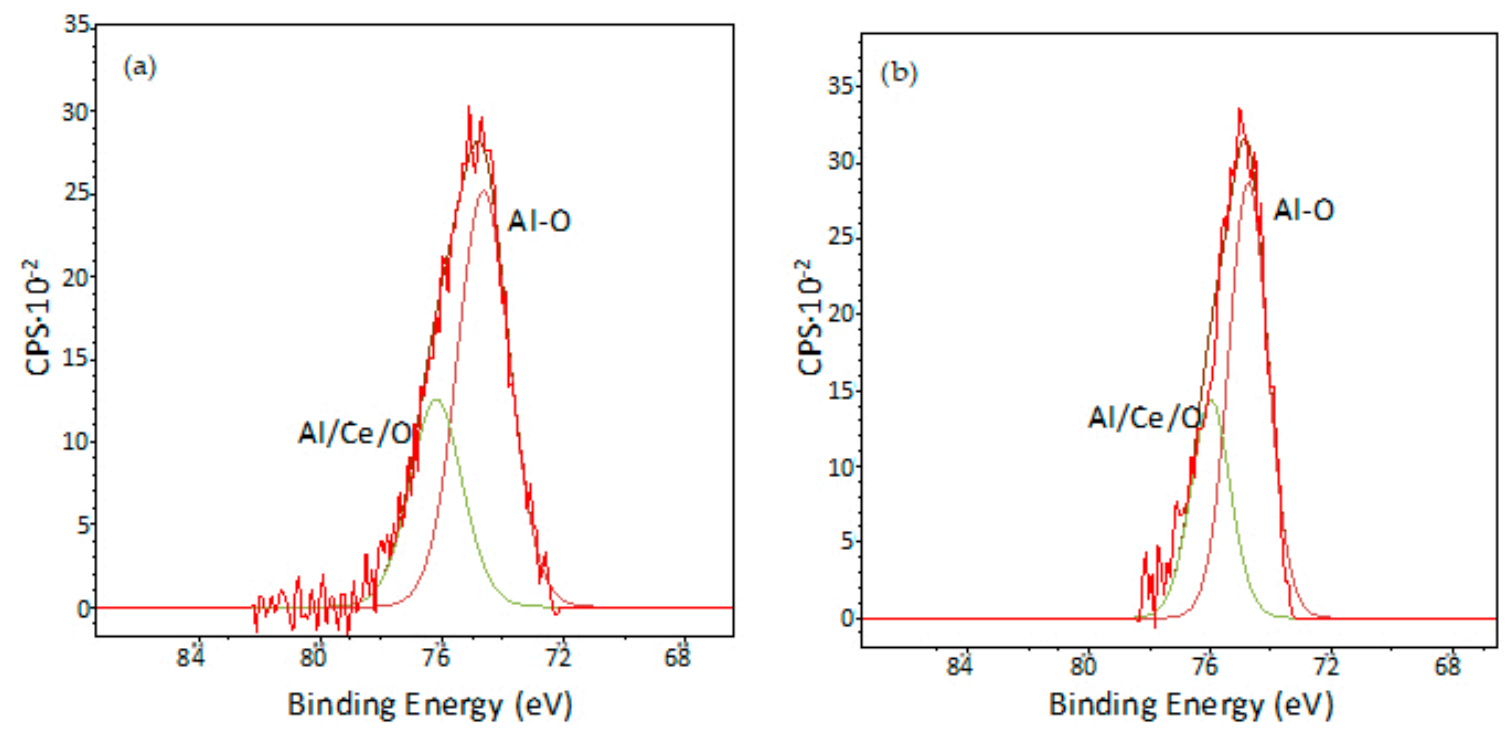

Figure 14. XPS spectra of Al2p. (a) CeCC-1. (b) CeCC-2.

High resolution XPS spectra of fitted peaks of O1s signals can be observed in Figure 15. The experimental spectrum of CeCC-1 has two peaks partially overlapped. Meanwhile, CeCC-2 has two peaks very close and almost completely overlapped. The signals are fitted to the bonds $\mathrm{Ce}-\mathrm{OH}$, $\mathrm{Ce}-\mathrm{O}$ and Al-O [37]. Signals corresponding to the $\mathrm{Ce}-\mathrm{OH}$ and $\mathrm{Ce}-\mathrm{O}$ bonds occur at 532.0 and 529.8 $\mathrm{eV}$, respectively. In addition, the third signal is the smallest and is located at $531.8 \mathrm{eV}$ in $\mathrm{CeCC}-1$ and at $530.7 \mathrm{eV}$ in $\mathrm{CeCC}-2$, associated to the group Al-O. The ratio [Ce]/[Al] have been calculated by assigning the sum of areas of the peaks $\mathrm{Ce}-\mathrm{OH}$ and $\mathrm{Ce}-\mathrm{O}$ to [Ce] and the area of $\mathrm{Al}-\mathrm{O}$ to [Al]. The results indicate a ratio $[\mathrm{Ce}] /[\mathrm{Al}]=10.4$ for $\mathrm{CeCC}-1$ and 33.8 for CeCC-2. 

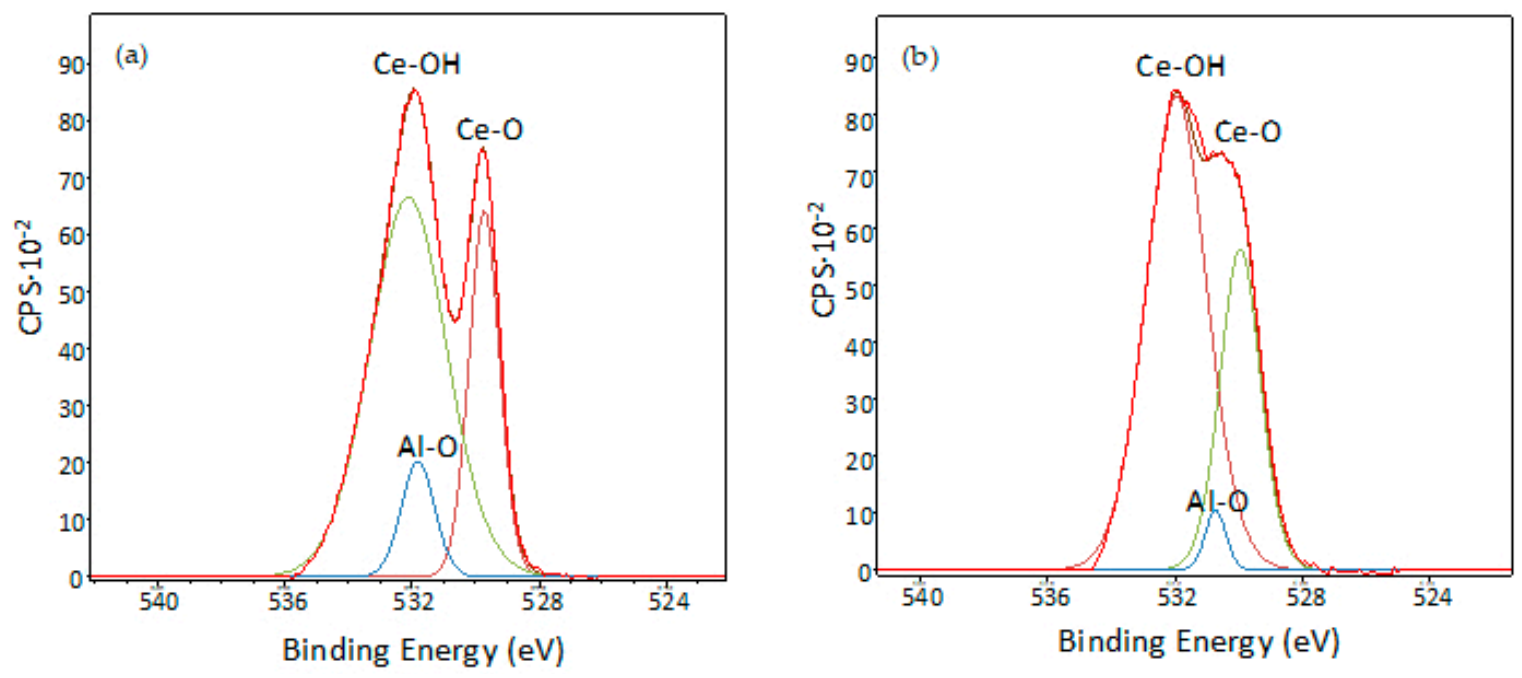

Figure 15. XPS spectra of O1s. (a) CeCC-1, (b) CeCC-2.

\section{Discussion}

The characterisation of samples Pretreated 1 and 2 by means of SEM-EDS of Figures $2-4$ allowed us to monitor the effects of the pretreatments on the main intermetallic particles of the aluminium alloy 2024-T3. Neither $\mathrm{Al}(\mathrm{Cu}, \mathrm{Mg})$ nor Al-Cu-Fe-Mn-(Si) phases exhibit modification on sample Pretreated 1 when compared to samples Not Treated. Likewise, there are no evident changes in Al-Cu-Fe-Mn-(Si) intermetallics of sample Pretreated 2 after immersion in the acid bath (Smut Go NC).

Regarding $\mathrm{Al}(\mathrm{Cu}, \mathrm{Mg})$ phases in sample Pretreated 2, the analysis of the cavities left by particles disappeared in sample Pretreated 2 have shown a similar composition to the aluminium matrix, Figure 5. In the case of $\mathrm{Al}(\mathrm{Cu}, \mathrm{Mg})$ phases with sponge appearance that still remain after Pretreatment 2 present a high reduction in $\mathrm{Mg}$ and $\mathrm{Al}$ atomic \% and an increase in $\mathrm{Cu}$ atomic \%. These results are in good agreement with other authors [39-41] that describe the dissolution of the phase $\mathrm{Al}(\mathrm{Cu}$, $\mathrm{Mg}$ ) in an oxidant or corrosive medium proceeding with an initial dealloying in $\mathrm{Mg}$, followed by other dealloying in $\mathrm{Al}$ which produce an enriching of particles in $\mathrm{Cu}$ and a final detachment of the $\mathrm{Al}(\mathrm{Cu}, \mathrm{Mg})$ particles. The dissolution of $\mathrm{Mg}$ and $\mathrm{Al}$ are justified by the anodic behaviour of this phase against the aluminium matrix. The anodic reactions are the oxidation of $\mathrm{Mg}$ and $\mathrm{Al}$, Equations (2) and (3), while the reduction of oxygen to $\mathrm{OH}^{-}$takes place as the cathodic response, Equation (4).

$$
\begin{gathered}
\mathrm{Mg} \rightarrow \mathrm{Mg}^{2+}+2 \mathrm{e}^{-} \\
\mathrm{Al} \rightarrow \mathrm{Al}^{3+}+3 \mathrm{e}^{-} \\
\frac{1}{2} \mathrm{O}_{2}+\mathrm{H}_{2} \mathrm{O}+2 \mathrm{e}^{-} \rightarrow 2 \mathrm{OH}^{-} \\
\mathrm{Al}_{2} \mathrm{O}_{3}+2 \mathrm{OH}^{-} \rightarrow 2 \mathrm{AlO}_{2}{ }^{-}+\mathrm{H}_{2} \mathrm{O}
\end{gathered}
$$

When comparing the initial atomic \% of the $\mathrm{Al}(\mathrm{Cu}, \mathrm{Mg})$ particles that became afterwards detached and dealloyed but not detached, shown in Figure 5, it can be found that the former ones have a lower content of aluminium, approximately $60 \%$ vs. $70 \%$, and a higher amount of magnesium, $20 \% \mathrm{vs.} 10 \%$, than the latter ones. Meanwhile, the copper content is close to $20 \%$ in both cases. These differences are coherent with the dealloying mechanism mentioned above, since it is reasonable that those phases losing less volume in form of $\mathrm{Mg}^{2+}$ remain in their places, and vice versa, those losing a higher amount in form of $\mathrm{Mg}^{2+}$ became detached. According to this, those $\mathrm{Al}(\mathrm{Cu}, \mathrm{Mg})$ phases that are still on the surface after Pretreatment 2 may had higher proportion of $\mathrm{Al} 2 \mathrm{Cu}, \theta$-Phase, than those ending detached.

In addition, it can be noticed that the atomic \% of aluminium keep unchanged within samples Not Treated, Pretreated 1 and Pretreated 2. Therefore, according again to the assumed mechanism, either 
the experimental parameters employed in the bath with Smut Go NC, concentration, temperature and time, are not enough to reach the final stage in which the aluminium is oxidised, or, alternatively, if this stage is already in progress, the intermetallic particles have been removed away from the matrix and they cannot be analysed.

Several authors establish $\mathrm{Al}(\mathrm{Cu}, \mathrm{Mg})$ as main phase responsible of pitting corrosion of $\mathrm{Al}-\mathrm{Cu}$ alloys in chloride media due to their anodic behaviour [16,33,34,42], i.e., oxidation of $\mathrm{Mg}$ and $\mathrm{Al}$, Equations (1) and (2). The counterpart reduction of oxygen to $\mathrm{OH}^{-}$, Equation (3), provokes the local increase of the $\mathrm{pH}$ near the $\mathrm{Al}(\mathrm{Cu}, \mathrm{Mg})$ and subsequently the dissolution of the alumina layer and the neighbouring aluminium, Equation (4). As a consequence, specimens with less quantity of $\mathrm{Al}(\mathrm{Cu}, \mathrm{Mg})$ particles, Pretreated 2, are expected to give a potentiodynamic polarisation curve moved to lower current zones than specimens with higher number of $\mathrm{Al}(\mathrm{Cu}, \mathrm{Mg})$ particles, Not Treated and Pretreated 1. LP curves of samples Not Treated, Pretreated 1 and Pretreated 2 in Figure 9 and their corresponding $R_{\mathrm{p}}$ values of $955 \simeq 1068<6407 \Omega \cdot \mathrm{cm}^{2}$ in Table 2 are coherent with this discussion.

It is known that the formation of cerium-based conversion coatings proceeds over and around intermetallic particles, both anodic and cathodic against the aluminium matrix, although via different mechanisms depending on the electrochemical behaviour of the intermetallic [31]. It has been also described that the coating forms on other electrochemically active areas such as grain boundaries or rolling marks made during manufacturing $[11,43,44]$. In our work, on one hand, microanalysis by SEM-EDS of samples CeCC- 1 and CeCC-2 with 15 min and only 3 min of cerium treatment confirmed that $\mathrm{Al}(\mathrm{Cu}, \mathrm{Mg})$ intermetallic and $\mathrm{Al}-\mathrm{Cu}-\mathrm{Fe}-\mathrm{Mn}-(\mathrm{Si})$ phases are seeds for the deposition of the coating, as described in Figures 6-8. It was also stated that there are higher number of cerium island formed over intermetallic particles in sample CeCC-1, especially those which consist on an area rich in copper and cerium surrounded by another area rich in cerium due to the CeCC deposition on the intermetallic $\mathrm{Al}(\mathrm{Cu}, \mathrm{Mg})$. On the other hand, SEM images like Figure $7 \mathrm{~b}$ suggest preferential deposition along rolling marks direction in the case of sample CeCC-2. The etching of the native alumina by the Smut Go NC solution may expose cathodic areas on the ridges of the rolling marks which promote $\mathrm{H}_{2} \mathrm{O}_{2}$ reduction and cerium deposition [45].

When comparing the characterisation results described in the previous paragraph, with the electrochemical behaviour of samples CeCC-1 and CeCC-2 in Figures 9 and 10, it seems reasonable that the changes suffered by $\mathrm{Al}(\mathrm{Cu}, \mathrm{Mg})$ during Smut Go NC acid treatment influence the formation process of the cerium/alumina coating and its corrosion resistance. Hence, as shown in Tables 2 and 3 , sample CeCC-1 gives higher $R_{\mathrm{p}}$ and higher impedance than sample CeCC-2: $1.23 \times 10^{5}$ vs. $1.99 \times$ $10^{4} \Omega \cdot \mathrm{cm}^{2}$ and $1.8 \times 10^{4}$ vs. $1.2 \times 10^{4} \Omega \cdot \mathrm{cm}^{2}$. Furthermore, the optical image of the CeCC- 1 is more homogeneous than CeCC-2, Figure 6.

XPS analysis were performed with the aim of further understand the reasons behind the different corrosion performance of the cerium coatings. The first general conclusion obtained from the survey spectra in Figure 12 and composition in Table 4 is that CeCC- 1 has a content of cerium two-fold of CeCC-2, $5.98 \%$ vs. $2.79 \%$ on the surface of the coating. Aluminium and oxygen, however, exhibit very low differences. Copper, although in a very low proportion, seems to be higher in sample CeCC-2, which can be explained for the redeposition on the surface of copper previously etched from the alloy during the treatment in Smut Go NC [31].

The estimation of $\mathrm{Ce}^{4+\%}$ employing the peak $\mathrm{u}^{\prime \prime \prime}$ in the XPS spectra of Ce3d signals, Figure 13, concluded that $\mathrm{Ce}^{4+}$ is predominant in the surface of all coatings obtained, being $\mathrm{Ce}^{3+}$ in lower proportion. This result has been reported by other authors employing $\mathrm{H}_{2} \mathrm{O}_{2}$ as oxidant, leading to improvements in the corrosion behaviour of the cerium conversion coatings $[18,46]$. $\mathrm{Ce}^{4+\%}$ was higher in CeCC-1 (between 97-100\%) than in CeCC-2 (between 66-86\%), which is in agreement with the better corrosion behaviour of CeCC-1 in polarisation curve (higher $R_{\mathrm{p}}$, Table 2) and EIS analysis (higher $R_{\mathrm{c}}$, Table 3) and with the higher population of intermetallic particles observed by SEM. The oxidant power of $\mathrm{H}_{2} \mathrm{O}_{2}$, the presence of intermetallic phases and oxidation of sample in air are the three factors reported in the literature to explain the oxidation of $\mathrm{Ce}^{3+}$ to $\mathrm{Ce}^{4+}$ in these coatings [32,47-49]. In our 
case, the concentration of $\mathrm{H}_{2} \mathrm{O}_{2}$ is the same and the samples were prepared and analysed at the same time. Therefore, the different number and type of intermetallics is the fact most likely to explain the different content of $\mathrm{Ce}^{4+}$ and $\mathrm{Ce}^{3+}$.

XPS spectra in Figure 14 also indicate that aluminium/cerium mixed oxide domains together with alumina coexist in both samples $\mathrm{CeCC}-1$ and $\mathrm{CeCC}-2$, since there are peaks associated to $\mathrm{Al} / \mathrm{Ce} / \mathrm{O}$ and Al-O in the signal Al2p. In addition, the absence of Al-Al signal may show that the mixed oxide and alumina forms a coating thick enough to prevent the XPS analysis to reach the bulk of the alloy.

Experimental O1s signals in Figure 15 have different shapes in the spectra of samples CeCC-1 and CeCC-2 due to a displacement of $\simeq 1 \mathrm{eV}$ in the peak fitted for Al-O bond. The difference may be caused by a different chemical environment of $\mathrm{Al}-\mathrm{O}$ in the two samples. Moreover, the ratio $[\mathrm{Ce}] /[\mathrm{Al}]$, based on the area of $\mathrm{Ce}-\mathrm{OH}, \mathrm{Ce}-\mathrm{O}$ and $\mathrm{Al}-\mathrm{O}$, is three times higher for CeCC-2 with respect $\mathrm{CeCC}-1$. In other words, sample CeCC-2 has a major proportion of its total oxygen in form of cerium oxide/hydroxide than sample CeCC-1.

\section{Conclusions}

A standard surface pretreatment chain of aluminium alloys in the aerospace industry has been studied for the preparation of cerium conversion coatings on aluminium-copper alloy 2024-T3. The results show that the cerium-based coating formed after the employment of only part of the chain (Pretreatment 1) has better corrosion behaviour than applying the whole chain (Pretreatment 2).

Alloy phases have a great influence in the chemical conversion coatings formation on $\mathrm{Al}-\mathrm{Cu}$ alloys, especially those known as $\mathrm{Al}(\mathrm{Cu}, \mathrm{Mg})$, a mixture of $\mathrm{Al}_{2} \mathrm{CuMg}$ and $\mathrm{Al}_{2} \mathrm{Cu}$, that have a anodic activity against the matrix. Standard products employed as pretreatments for $\mathrm{CrCC}$ in the aerospace industry have different effect on these particles.

SEM-EDX quantification revealed that pretreatment accomplished in two steps employing alkaline degreaser Turco 6849 and alkaline cleaner Turco 4215 NC-LT (Pretreatment 1) have no effect on $\mathrm{Al}-\mathrm{Cu}-\mathrm{Mn}-\mathrm{Fe}-(\mathrm{Si})$ and $\mathrm{Al}(\mathrm{Cu}, \mathrm{Mg})$. However, after including a last acid pickling pretreatment step with Smut Go NC (Pretreatment 2), $\mathrm{Al}(\mathrm{Cu}, \mathrm{Mg})$ phases are total or partially removed depending on the content of $\mathrm{Al}_{2} \mathrm{Cu}$, with distinct dealloying due to selective leaching of magnesium and aluminium.

Polarisation curves results after Pretreatment 2 showed a displacement of the cathodic branch toward lower current densities. These results reveal that both $\mathrm{Al}(\mathrm{Cu}, \mathrm{Mg})$ phases that still remain on the surface and unaffected Al-Cu-Mn-Fe-(Si) phases work as cathodes, promoting fast anodic dissolution of aluminium.

CeCC deposited after Pretreatment 1 and Pretreatment 2 gave three main features: areas with dried-mud cerium coating over the matrix, cerium island over intermetallic phases and apparently free-coating areas. Samples CeCC-1 have better corrosion behaviour than samples CeCC-2. This result has been associated to a larger population of intermetallic in the surface of sample CeCC-1, which in turn leads to a higher content of cerium in the coating and a higher proportion of $\mathrm{Ce}^{4+}$.

A general concern derived from the results obtained in this investigation is that acid etching step should be avoided if a CeCC is intended to be developed in 2024 alloy.

Once the standard pretreatment chain has been adapted for the deposition of cerium in presence of $\mathrm{H}_{2} \mathrm{O}_{2}$, the future work will involve the optimization of the cerium bath parameters, such as cerium salt concentration, $\mathrm{pH}$ and/or $\mathrm{H}_{2} \mathrm{O}_{2}$ concentration, to finally assess the employment of the whole process as an alternative to chromate-based conversion coatings.

Author Contributions: Conceptualization, L.G.R., M.B. and F.J.B.; methodology, L.G.R., M.B. and J.J.A.G.; formal analysis, L.G.R., M.B. and J.J.A.G.; investigation, J.J.A.G.; resources, F.J.B.; writing-original draft preparation, J.J.A.G. and L.G.R.; writing-review and editing, M.B. and J.M.S.A.

Funding: This research was funded by the Ministry of Economy, Industry and Competitiveness of Spain/FEDER Program of the EU. Project: Optimización y viabilidad industrial del proceso de preparación de capas de conversión basadas en cerio sobre aleaciones de aluminio. Reference MAT2014-60857-R. 
Acknowledgments: The authors would also like to acknowledge Titania, Ensayos y Proyectos Industriales S.L. for the support in the achievements of this work. L.G.R. acknowledges support from the Programme for Attracting Talent of UCA (Vice-rectorate for Technology Transfer and Innovation). J.J.A.G. acknowledges Vice-rectorate for Research of UCA (Contratos predoctorales PIF, Plan Propio 2015).

Conflicts of Interest: The authors declare no conflict of interest.

\section{References and Note}

1. Guillaumin, V.; Mankowski, G. Localized corrosion of 2024 T351 aluminium alloy in chloride media. Corros. Sci. 1998, 41, 421-438. [CrossRef]

2. Jones, M.J.; Heurtier, P.; Desrayaud, C.; Montheillet, F.; Allehaux, D.; Driver, J.H. Correlation between microstructure and microhardness in a friction stir welded 2024 aluminium alloy. Scr. Mater. 2005, 52, 693-697. [CrossRef]

3. Hughes, A.E.; Glenn, A.M.; Wilson, N.; Moffatt, A.; Morton, A.J.; Buchheit, R.G. A consistent description of intermetallic particle composition: An analysis of ten batches of AA2024-T3. Surf. Interface Anal. 2013, 45, 1558-1563. [CrossRef]

4. Hughes, A.E.; Parvizi, R.; Forsyth, M. Microstructure and corrosion of AA2024. Corros. Rev. 2015, 33, 1-30. [CrossRef]

5. Zhang, F.; Levine, L.E.; Allen, A.J.; Campbell, C.E.; Creuziger, A.A.; Kazantseva, N.; Ilavsky, J. In situ structural characterization of ageing kinetics in aluminum alloy 2024 across angstrom-to-micrometer length scales. Acta Mater. 2016, 111, 385-398. [CrossRef] [PubMed]

6. Boag, A.; Hughes, A.E.; Wilson, N.C.; Torpy, A.; MacRae, C.M.; Glenn, A.M.; Muster, T.H. How complex is the microstructure of AA2024-T3? Corros. Sci. 2009, 51, 1565-1568. [CrossRef]

7. De Rose, J.A.; Suter, T.; Balkowiec, A.; Michalski, J.; Kurzydlowski, K.J.; Schmutz, P. Localised corrosion initiation and microstructural characterization of an Al 2024 alloy with a higher $\mathrm{Cu}$ to $\mathrm{Mg}$ ratio. Corros. Sci. 2012, 55, 313-325. [CrossRef]

8. Eichinger, E.; Osborne, J.; Van Cleave, T. Hexavalent chromium elimination: An aerospace industry progress report. Metal Finish. 1997, 95, 36-41. [CrossRef]

9. Qi, J.; Gao, L.; Li, Y.; Wang, Z.; Thompson, G.E.; Skeldon, P. An optimized trivalent chromium conversion coating process for AA2024-T351 alloy. J. Electrochem. Soc. 2017, 164, 390-395. [CrossRef]

10. Kendig, M.W.; Buchheit, R.G. Corrosion inhibition of aluminum and aluminum alloys by soluble chromates, chromate coatings, and chromate-free coatings. Corrosion 2003, 59, 379-400. [CrossRef]

11. Wu, J.; Peng, D.; He, Y.; Du, X.; Zhang, Z.; Zhang, B.; Li, X.; Huang, Y. In situ formation of decavanadate-intercalated layered double hydroxide films on AA2024 and their anti-corrosive properties when combined with hybrid sol gel films. Materials 2017, 10, 426. [CrossRef] [PubMed]

12. Montemor, M.F. Functional and smart coatings for corrosion protection: A review of recent advances. Surf. Coat. Technol. 2014, 258, 17-37. [CrossRef]

13. Momtemor, F. Fostering green inhibitors for corrosion prevention. In Active Protective Coatings New-Generation Coatings for Metals, 1st ed.; Hughes, A.E., Mol, J.M.C., Eds.; Springer Netherlands: Dordrecht, The Netherlands, 2016; Volume 233, pp. 107-137.

14. Bethencourt, M.; Botana, F.J.; Calvino, J.; Marcos, M.; Rodríguez-Chacón, M.A. Anthanide compounds as environmentally-friendly corrosion inhibitors of aluminium alloys: A review. Corros. Sci. 1998, 40, 1803-1919. [CrossRef]

15. Harvey, T.G. Cerium-based conversion coatings on aluminium alloys: A process review. Corros. Eng. Sci. 2013, 48, 248-264. [CrossRef]

16. Campestrini, P.; Terryn, H.; Hovestad, A.; de Wit, J.H.W. Formation of a cerium-based conversion coating on AA2024: Relationship with the microstructure. Surf. Coat. Technol. 2003, 176, 365-391. [CrossRef]

17. Palomino, L.E.M.; Aoki, I.V.; de Melo, H.G. Microstructural and electrochemical characterization of Ce conversion layers formed on $\mathrm{Al}$ alloy 2024-T3 covered with Cu-rich smut. Electrochim. Acta 2006, 51, 5943-5953. [CrossRef]

18. Buchheit, R.G.; Mamidipally, S.B.; Schmutz, P.; Guan, H. Active corrosion protection in Ce-modified hydrotalcite conversion coatings. Corrosion 2002, 58, 3-14. [CrossRef] 
19. Edington, J.; Padwal, A.; Williams, A.; O'Keefe, J.; O'Keefe, T.J. Metal surface preparation tips. Metal. Finish. 2005, 103, 38-41. [CrossRef]

20. De Frutos, A.; Arenas, M.A.; Liub, Y.; Skeldon, P.; Thompson, G.E.; de Damborenea, J.; Conde, A. Influence of pre-treatments in cerium conversion treatment of AA2024-T3 and 7075-T6 alloys. Surf. Coat. Technol. 2008, 202, 3797-3807. [CrossRef]

21. Airbus Operation S.L. Specification I+D-P-072: Limpieza y decapado del aluminio y sus aleaciones. Last revision: 17 July 2017. (In Spainish)

22. Liangliang, L.; Desouza, A.L.; Swain, G.M. Effect of deoxidation pretreatment on the corrosion inhibition provided by a trivalent chromium process (TCP) conversion coating on AA2024-T3. J. Electrochem. Soc. 2014, 161, 246-253.

23. Guo, Y.; Frankel, G.S. Characterization of trivalent chromium process coating on AA2024-T3. Surf. Coat. Technol. 2012, 206, 3895-3902. [CrossRef]

24. Viroulaud, R.; Swiatowska, J.; Seyeux, A.; Zanna, S.; Tardelli, J.; Marcus, P. Influence of surface pretreatments on the quality of trivalent chromium process coatings on aluminum alloy. Appl. Surf. Sci. 2017, 423, 927-938. [CrossRef]

25. Pinc, W.; Geng, S.; O'Keefe, M.; Fahrenholtz, W.; O'Keefe, T. Effects of acid and alkaline based surface preparations on spray deposited cerium based conversion coatings on Al 2024-T3. Appl. Surf. Sci. 2009, 255, 4061-4065. [CrossRef]

26. Stern, M.; Geary, A.L. Electrochemical polarization: I. A theoretical analysis of the shape of polarization curves. J. Electrochem. Soc. 1957, 104, 56-63. [CrossRef]

27. Matter, E.A.; Kozhukharov, S.; MacHkova, M.; Kozhukharov, V. Electrochemical studies on the corrosion inhibition of AA2024 aluminium alloy by rare earth ammonium nitrates in $3.5 \% \mathrm{NaCl}$ solutions. Mater. Corros. 2013, 64, 408-414. [CrossRef]

28. Campestrini, P.; Van Westing, E.P.M.; Van Rooijen, H.W.; de Wit, J.H.W. Relation between microstructural aspects of AA2024 and its corrosion behaviour investigated using AFM scanning potential technique. Corros. Sci. 2000, 42, 1853-1861. [CrossRef]

29. Hughes, A.E.; Harvey, T.G.; Nikpour, T.; Muster, T.H.; Hardin, S.G. Non-chromate deoxidation of AA2024-T3 using Fe(III)-HF-HNO3. Surf. Interface Anal. 2004, 36, 15-23. [CrossRef]

30. Glenn, A.M.; Hughes, A.E.; Muster, T.H.; Lau, D.; Wilson, N.C.; Torpy, A.; MacRae, C.M.; Ward, J. Investigation into the influence of carbon contamination on the corrosion behavior of Aluminum microelectrodes and AA2024-T3. J. Electrochem. Soc. 2013, 160, 119-127. [CrossRef]

31. Lau, D.; Glenn, A.M.; Hughes, A.E.; Scholes, F.H.; Muster, T.H.; Hardin, S.G. Factors influencing the deposition of Ce-based conversion coatings, Part II: The role of localised reactions. Surf. Coat. Technol. 2009, 203, 2937-2945. [CrossRef]

32. Hughes, A.E.; Scholes, F.H.; Glenn, A.M.; Lau, D.; Muster, T.H.; Hardin, S.G. Factors influencing the deposition of Ce-based conversion coatings, part I: The role of $\mathrm{Al}^{3+}$ ions. Surf. Coat. Technol. 2009, 203, 2927-2936. [CrossRef]

33. Dabalà, M.; Ramous, E.; Magrini, M. Corrosion resistance of cerium-based chemical conversion coatings on AA5083 aluminium alloy. Mater. Corros. 2004, 55, 381-386. [CrossRef]

34. Sánchez-Amaya, J.M.; Blanco, G.; García-García, F.J.; Bethencourt, M.; Botana, F.J. XPS and AES analyses of cerium conversion coatings generated on AA5083 by thermal activation. Surf. Coat. Technol. 2012, 213, 105-116. [CrossRef]

35. Uhart, A.; Ledeuil, J.B.; Gonbeau, D.; Dupin, J.V.; Bonino, J.P.; Ansart, F.; Esteban, J. An auger and XPS survey of cerium active corrosion protection forAA2024-T3 aluminum alloy. Appl. Surf. Sci. 2016, 390, 751-759. [CrossRef]

36. Shyu, J.Z.; Otto, K.; Watkins, W.L.H.; Graham, G.W. Characterization of $\mathrm{Pd} / \gamma$-alumina catalysts containing ceria. J. Catal. 1988, 114, 23-33. [CrossRef]

37. Heller, D.K.; Fahreholtz, W.G.; O'Keefe, M.J. The effect of post-treatment time and temperature on cerium-based conversion coatings on Al 2024-T3. Corros. Sci. 2010, 52, 360-368. [CrossRef]

38. Yu, X.; Li, G. XPS study of cerium conversion coating on the anodized 2024 aluminum alloy. J. Alloys Compd. 2004, 364, 193-198. [CrossRef]

39. Lacroix, L.; Ressier, L.; Blanc, C.; Mankowski, G. Statistical study of the corrosion behaviour of $\mathrm{Al} 2 \mathrm{CuMg}$ intermetallics in AA2024-T351 by SKPFM. J. Electrochem. Soc. 2008, 155, 8-15. [CrossRef] 
40. Lacroix, L.; Ressier, L.; Blanc, C.; Mankowski, G. Combination of AFM, SKPMF and SIMD to study the corrosion behaviour of S-phase particles in AA2024-T351. J. Electrochem. Soc. 2008, 155, 131-137. [CrossRef]

41. Li, J.; Dang, J. A summary of corrosion properties of Al-rich solid solution and secondary phases particles in Al alloys. Metals 2017, 7, 84. [CrossRef]

42. Aballe, A.; Bethencourt, M.; Botana, F.J.; Marcoa, M.; Sánchez-Amaya, J.M. Influence of the degree of polishing of alloy AA 5083 on its behaviour against localised alkaline corrosion. Corros. Sci. 2004, 46, 1909-1920. [CrossRef]

43. Mishra, A.K.; Balasubramaniam, R. Corrosion inhibition of aluminium by rare earth chloride. Mater. Chem. Phys. 2007, 103, 385-393. [CrossRef]

44. Bethencourt, M.; Botana, F.J.; Cano, M.J.; González-Rovira, L.; Marcos, M.; Sánchez-Amaya, J.M. Protection by thermal and chemical activation with cerium salts of the alloy AA2017 in aqueous solutions of $\mathrm{NaCl}$. Metall. Mater. Trans. A 2012, 43, 182-194. [CrossRef]

45. Hughes, A.E.; Gorman, J.D.; Miller, P.R.; Sexton, B.A.; Paterson, P.J.K.; Taylor, R.J. Development of cerium-based conversion coatings on 2024-T3 Al alloy after rare-earth desmutting. Surf. Interface Anal. 2004, 36, 290-303. [CrossRef]

46. Dabalà, M.; Armelao, L.; Buchberger, A.; Calliari, I. Cerium-based conversion layers on aluminum alloys. Appl. Surf. Sci. 2001, 172, 312-322. [CrossRef]

47. Decroly, A.; Petijean, J.P. Study of the deposition of cerium oxide by conversion on to aluminium alloy. Surf. Coat. Technol. 2005, 194, 1-9. [CrossRef]

48. Scholes, F.H.; Soste, C.; Hughes, A.E.; Hardin, S.G.; Curtis, P.R. The role of hydrogen peroxide in the deposition of cerium-based conversion coatings. Appl. Surf. Sci. 2006, 253, 1770-1780. [CrossRef]

49. Hughes, A.E.; Gorman, J.D.; Paterson, P.J.K. The characterisation of Ce-Mo-based conversion coatings on Al-alloys: Part, I. Corros. Sci. 1996, 38, 1957-1976. [CrossRef]

(C) 2019 by the authors. Licensee MDPI, Basel, Switzerland. This article is an open access article distributed under the terms and conditions of the Creative Commons Attribution (CC BY) license (http:/ / creativecommons.org/licenses/by/4.0/). 